\title{
Article \\ A Study on Anti-Shock Performance of Marine Diesel Engine Based on Multi-Body Dynamics and Elastohydrodynamic Lubrication
}

\author{
Liang Chen ${ }^{1}\left(\mathbb{D}\right.$, Dongxin Xue ${ }^{1}$, Xigeng Song ${ }^{1, *}$, Zhaoqi $\mathrm{He}^{1}$ and Dongjie Huang ${ }^{2}$ \\ 1 Institute of Internal Combustion Engine, School of Energy and Power Engineering, \\ Dalian University of Technology, Dalian 116024, China; chenlemail@mail.dlut.edu.cn (L.C.); \\ xuedx@dlut.edu.cn (D.X.); gshezhaoqi@mail.dlut.edu.cn (Z.H.) \\ 2 Training Department, Guangzhou Staff Training Base, China Railway Guangzhou Group Co. Ltd., \\ Guangzhou 510800, China; huangdjgz@outlook.com \\ * Correspondence: songxgdlut@hotmail.com; Tel.: +86-411-8470727
}

check for updates

Citation: Chen, L.; Xue, D.; Song, X.; He, Z.; Huang, D. A Study on Anti-Shock Performance of Marine Diesel Engine Based on Multi-Body Dynamics and Elastohydrodynamic Lubrication. Appl. Sci. 2021, 11, 11259. https://doi.org/10.3390/ app112311259

Academic Editors: Chang Yong Song and Wu Deng

Received: 3 October 2021

Accepted: 23 November 2021

Published: 27 November 2021

Publisher's Note: MDPI stays neutral with regard to jurisdictional claims in published maps and institutional affiliations.

Copyright: (c) 2021 by the authors. Licensee MDPI, Basel, Switzerland. This article is an open access article distributed under the terms and conditions of the Creative Commons Attribution (CC BY) license (https:// creativecommons.org/licenses/by/ $4.0 /)$.
Abstract: Diesel engine anti-shock performance is important for navy ships. The calculation method is a fast and economic way compared to underwater explosion trial in this field. Researchers of diesel engine anti-shock performance mainly use the spring damping model to simulate the main bearings of a diesel engine. The elastohydrodynamic lubrication method has been continuously used in the main bearings of diesel engines in normal working conditions. This research aims at using the elastohydrodynamic lubrication method in the main bearings of the diesel engine in external shock conditions. The main bearing elastohydrodynamic lubrication and diesel engine multi-body dynamics analysis is based on AVL EXCITE Power Unite software. The external shock is equivalent to the interference on the elastohydrodynamic lubrication calculation. Whether the elastohydrodynamic lubrication algorithm can complete the calculation under interference is the key to the study. By adopting a very small calculation step size, a high number of iterations, and increasing the stiffness of the thrust bearing, the elastohydrodynamic lubrication algorithm can be successfully completed under the external impact environment. The calculation results of the accelerations on engine block feet have a similar trend as the experiment results. Diesel engines with and without shock absorbers in external shock conditions are calculated. This calculation model can also be used for diesel engine dynamics calculations and main bearing lubrication calculations under normal working conditions.

Keywords: diesel engine; anti-shock; multi-body dynamics; elastohydrodynamic lubrication; main bearing; crankshaft; stress

\section{Introduction}

The research of shipboard equipment anti-shock performance can be divided into two methods: shock tests and calculations. The cost of underwater explosion trials on a real ship is very expensive, the preparation period is very long, and it faces huge pressure from the public opinion on marine environmental protection [1]. The aim of calculation method is to calculate the impact environment of shipboard equipment through the mathematical and mechanical models to obtain the equipment dynamic characteristics and predict its antishock performance. This method is cheap in cost, short in time, and easy to repeat. Diesel engines are commonly used power equipment on ships. The external impact strength is often much greater than the impact load generated by the diesel engine. As a machine with multiple moving parts and complex contact relationships between moving parts, the diesel engine should be investigated for an appropriate calculation method [2-5].

The anti-shock analysis of diesel engines mostly uses the time-domain calculation method. Diesel engines contain a variety of moving parts such as crankshafts, connecting rods, and pistons, and the external shocks generally last long. In order to reduce the number of calculations, the multi-body dynamics method is generally used. 
The crankshaft, connecting rod, and engine block are important parts of diesel engines. The calculation of the strength of these parts under external impact is an important content of diesel engine anti-shock performance research. From the works of the researchers, the crankshaft is greatly affected by external shocks, but the strength of the connecting rod is in safe range under the impact [6-9]. Z.J. Ming analyzed the shafting dynamics of a certain type of $16 \mathrm{~V} 240$ diesel engine in an explosion shock environment. It was found that the dynamic stress of the crankshaft is not greatly increased after impact and does not exceed the static yield limit of the crankshaft material with a large safety margin [10]. J.H. Ding et al. performed dynamic calculations on a large 16-cylinder V-type diesel engine assembly model under impact. From the calculation results, the maximum stress of each component is increased by dozens of MPa when the vertical impact is applied to the diesel engine in the running state, which does not exceed the yield limit of each material [11]. J.H. Zhao et al. calculated the shock response of the TBD234V6 diesel engine. The block stress far exceeds the safety limit. The vertical relative deformation between both ends of the first main journal reaches $0.2 \mathrm{~mm}$, which exceeds the range of the main bearing clearance. It is inferred that the lubricating oil film of the first main bearing will be damaged. Under the shock, the threads of diesel engine bolts cannot bear the impact load, and the bolts will separate, even bend or shear [12]. H.P. Gao et al. took a certain type of diesel generator as the research object and established a rigid-flexible multi-body dynamics model of the diesel engine, synchronous motor, common base, and vibration isolator. The stress of the crankshaft under normal operating conditions and external impact conditions does not exceed the yield limit of the crankshaft material [13].

In the underwater explosion test of a real ship, it was observed that the engine foot fasteners of the diesel engine were damaged by the impact, and the phenomenon was researched by calculations [14,15]. W.B. Wu simulated the shock resistance of a TBD234V6 diesel generator set. According to the calculation results, when a diesel engine is in the static state, the maximum stress of the diesel engine foot does not exceed the yield limit of the material in external impact [16].

Researchers have studied the overall impact response of external shocks on diesel engines and the weak position of diesel engine under external shocks $[17,18]$. Y.L. Xiao obtained the maximum stress and weak position of a 16VPA6 diesel engine through calculation in an external shock environment. By loading the calculation model with test data, the vertical acceleration response of the diesel engine foot is calculated and compared with the test data. The calculation and the experimental results are in good agreement with the trend [19].

There is a complicated contact relationship between the main journal and the main bearing of the diesel engine, and researchers mostly used the spring damping model to simulate it. In recent years, researchers tried to combine the multi-body dynamics with tribology in the diesel engine dynamics. B.J. Ma et al. calculated the influence of different oil film stiffnesses and bearing clearances on the calculation results of the shock response. From the calculation results, it can be concluded that the oil film stiffness has a greater impact on the shock response. With the increase in the oil film stiffness, the stress response of the structure tends to increase. The bearing clearance also has a greater influence on the shock response of the mechanism. As the bearing clearance increases, the stress response of the structure increases first and then decreases [8]. C. Ji et al. calculated the lubrication of diesel engine bearings in external impacts for a V-type six-cylinder diesel engine and used the difference method to solve the oil film pressure distribution of the sliding bearing, the maximum oil film pressure, and the maximum stress of alloy bearing. From the calculation results, the bearings are safe under impact [17]. The research of J. Sun et al. [20] and Z.X. He et al. [21] pointed out that the crankshaft bending has a significant impact on the local axis trajectory, the maximum oil film pressure, the minimum oil film thickness, the distribution of the oil film pressure, and other lubrication results.

The research of elastohydrodynamic lubrication theory is developing rapidly [22-31] and is widely used in the bearings of diesel engine [32-34]. X.B. Teng et al. increased 
the minimum oil film thickness of the main bearings by increasing the width of the oil groove and reducing the oil supply pressure [35]. Through research, L. Shi et al. found that the deformation of the main bearing hole directly affects the state of the oil film, and the improvement of the structure can reduce the wear on the contact surface [36]. $\mathrm{H}$. Li et al. studied the influence of surface roughness and texture direction on the bearing lubrication performance [37]. W. Zhou et al. analyzed the influence of bearing clearance, bearing width, oil supply pressure, and lubricating oil quality on the lubrication performance [38]. C.P. Liu et al. significantly reduced the asperity contact pressure and the wear on the bearing edge using the variable wall thickness design of the bearing bush [39]. J.H. Zhang et al. optimized the lubrication characteristics of the main bearing using an orthogonal experiment and neural network methods [40]. J. Wang et al. analyzed the influence of different surface topography and journal tilt on the distribution of oil film pressure and oil film thickness [41]. K. Liu et al. studied the influence of the crankshaft balance rate on the main bearing's minimum oil film thickness, maximum oil film pressure, shaft trajectory and lubricating oil filling rate [42]. X.Y. Yan et al. conducted an analysis on the elastohydrodynamic lubrication performance of the main bearing of a low-speed marine diesel engine [43,44]. J.H. Zhou studied the influence of journal deflection and tilt on oil film lubrication and wear [45]. X.K. Feng et al. [46] and W.D. Qian et al. [47] studied the thermal elastohydrodynamic lubrication of thrust bearings. J.X. Wang et al. [48] used a mixed thermal elastohydrodynamic model to study the hybrid lubrication phenomenon of sliding bearings under heavy load conditions. Z. P. Mourelatos [49], G. Offner [50], M.T. Ma [51] and V. Caika [52,53] coupled the dynamics of the crankshaft structure, the elastic deformation of the body, and the hydrodynamic lubrication of the bearing and analyzed the lubrication of the main bearing of the diesel engine. The co-simulation of multi-body dynamics and elastohydrodynamic lubrication of the diesel engine can be achieved.

In the diesel engine anti-shock performance research subject, researchers calculated different engine types from 4-cylinder in-line engines to 6-cylinder $V$ type engines to 16-cylinder $\mathrm{V}$ type engines. To simplify the research model, researchers often use the spring damping model to calculate the main bearings of the diesel engine. The elastohydrodynamic lubrication method has been continuously used on the main bearings of diesel engines in normal conditions. This research attempts to apply the elastohydrodynamic lubrication method to the main bearings of a diesel engine in external shock conditions. The external shock is equivalent to the interference on the elastohydrodynamic lubrication calculation. Whether the elastohydrodynamic lubrication algorithm can complete the calculation under interference is the key to the research. This research is aimed at the calculation of diesel engine lubrication under the impact environment, and the calculation model can also be used for diesel engine dynamics analysis and main bearing lubrication analysis under normal operating conditions.

\section{Methodology}

This paper establishes a diesel engine anti-shock calculation model based on multibody dynamics and the elastohydrodynamic lubrication method using diesel engine main bearing lubrication results and crankshaft stress results to evaluate whether the diesel engine can work normally under external impact.

\subsection{Theory}

In the model system, each direction of each particle in the elastic body obeys the laws of momentum and angular momentum, forming its dynamic equation. All the directions of all the particles in the elastic body constitute the dynamic equations [54-56]. The dynamic equation of the elastic body is as follows:

$$
[M]\{\ddot{x}\}+[D]\{\dot{x}\}+[K]\{x\}=\{f\}
$$

In Equation (1), $[M]$ is the mass matrix; $[K]$ is the structural dynamic stiffness matrix (varies with frequency); $[D]$ is the material dynamic damping (varies with frequency) and 
can be obtained by linear combination $[D]=a[M]+b[K] ;[x]$ is the displacement vector, reflecting global motion and local deformation; $[\dot{x}]$ and $[\ddot{x}]$ are the velocity vector and the acceleration vector, respectively; and $[f]$ is the load vector, including external loads and interactions between bodies.

$$
\begin{aligned}
& \frac{\partial}{\partial z}\left(\frac{1}{12 \eta} h^{3} \theta \frac{\partial p}{\partial z}\right)+\frac{\partial}{\partial x}\left(\frac{1}{12 \eta} h^{3} \theta \frac{\partial p}{\partial x}\right)= \\
& \theta \frac{u_{1}+u_{2}}{2} \frac{\partial h}{\partial x}+h \frac{u_{1}+u_{2}}{2} \frac{\partial \theta}{\partial x}+\frac{\partial(h \theta)}{\partial t}
\end{aligned}
$$

Based on the extended Reynolds equation, the elastohydrodynamic lubrication theory is used to establish a lubrication model for the main bearings of the diesel engine, taking into account the influence of the elastic deformation of the journal, the bearing, and the oil-filling state. The extended Reynolds equation is shown in Equation (2). $p$ is the oil film pressure; $\theta$ is the oil filling rate; $h$ is the oil film thickness; $\eta$ is the oil viscosity; $u_{1}$ and $u_{2}$ represents the speed of the journal and the bearing bush in the circumferential direction, respectively; $t$ is the time; $x$ and $z$ represent the coordinates along the circumferential direction and the coordinates along the axial direction, respectively (fixed bearing bush). From the calculation results of the elastohydrodynamic lubrication of the main bearings, the oil film state, the coupling effect between the elastic boundary and the oil film, and the oil inflow and outflow state can be found out in detail.

When the minimum oil film thickness of the main bearing is less than the composite roughness between the main journal and the main bearing, frictional contact occurs. This study uses the Greenwood-Tripp $[57,58]$ model to describe the asperity contact. It is assumed that the random change of the surface profile height to the reference plane obeys the Gaussian distribution, and the nominal pressure on the contact surface can be expressed as follows:

$$
p_{a}=\frac{16 \sqrt{2} \pi}{15}\left(\sigma_{s} \beta \eta_{s}\right)^{2} E^{*} \sqrt{\frac{\sigma_{s}}{\beta}} F_{5 / 2}\left(\frac{h}{\sigma_{s}}\right)
$$

In Equation (3), when $h / \sigma_{s}<4$, use the following formula to calculate $F_{5 / 2}$ :

$$
F_{5 / 2}=4.4086 \times 10^{-5}\left(4-\frac{h}{\sigma_{s}}\right)^{6.804}
$$

When $h / \sigma_{s} \geq 4$, use the following formula to calculate $F_{5 / 2}$ :

$$
F_{\frac{5}{2}}=0
$$

In Equation (3), use the following formula to calculate $E^{*}$ :

$$
E^{*}=\frac{1}{\left(\frac{1-v_{1}^{2}}{E_{1}}+\frac{1-v_{2}^{2}}{E_{2}}\right)}
$$

In Equation (3), $\sigma_{s}$ is the variance of the compound gap between rough contact surfaces; $\beta$ is the radius of contact point; $\eta_{s}$ is the peak density of contact surface; $h$ is the nominal gap between contact surfaces; $E_{1}$ and $E_{2}$ are the elastic modulus of upper and lower contact surface, respectively; and $v_{1}$ and $v_{2}$ is the Poisson's ratio of upper and lower contact surface, respectively. Equations (4) and (5) are used to explain how the coefficient $F_{5 / 2}$ plays a role in Equation (3). When the oil film thickness is high enough, the coefficient $F_{5 / 2}$ calculated by Equation (5) is zero, and the asperity contact pressure calculated by Equation (3) is zero. When the oil film thickness is low to a certain extent, the coefficient $f$ calculated by Equation (4) is not zero, and the corresponding asperity contact pressure is calculated by Equation (3). It can be seen from Equations (4) and (5) that the Equation (3) will only take effect when the oil film gap is low to a certain extent, and the smaller the oil film gap, the greater the frictional contact pressure. Using the Greenwood-Tripp model helps to quantitatively study the severity of frictional contact. The sum of the asperity contact 
pressure and the hydraulic oil film pressure is provided in the elastic body deformation calculation model of the main journals and the main bearings as the boundary condition.

\subsection{Simulation Model}

The main work of this paper is completed by MSC Patran, MSC Nastran and AVL EXCITE Power Unite (abbreviated as EXCITE) software. The crankshaft and block are created, meshed, and set material properties by MSC Patran. Export the bdf format model files of the crankshaft and the block from the Patran to the Nastran for the reduction. Set the main degree of freedom nodes of the crankshaft and block. The selection of the main degree of freedom nodes mainly considers the factors such as the action point of the external loads, the coupling point between moving parts, the distribution of the mass, and stiffness of the crankshaft and block. A schematic diagram of the main degree of freedom nodes model of the crankshaft of an in-line 4-cylinder engine after reduction is shown in Figure 1b. The blue dots in the Figure $1 \mathrm{~b}$ represents the main degree of freedom nodes, and these main degrees of freedom nodes are selected at the main journal, crank pin, output end, and free end of the crankshaft. The mass and inertia of the crankshaft and the block will be concentrated on these main degrees of freedom nodes after condensation. According to research needs, determine the number of crankshaft and block modes to be retained in the condensation. Then, use the modal analysis solver Sol 103 in Nastran for reduction. After reduction, the mass, inertia, and dynamic characteristics of the crankshaft and block are retained, and the total number of degrees of freedom of the crankshaft and block are reduced from several hundred thousand to several thousand. Through reduction, the calculation amount of the multi-body dynamics model can be reduced.

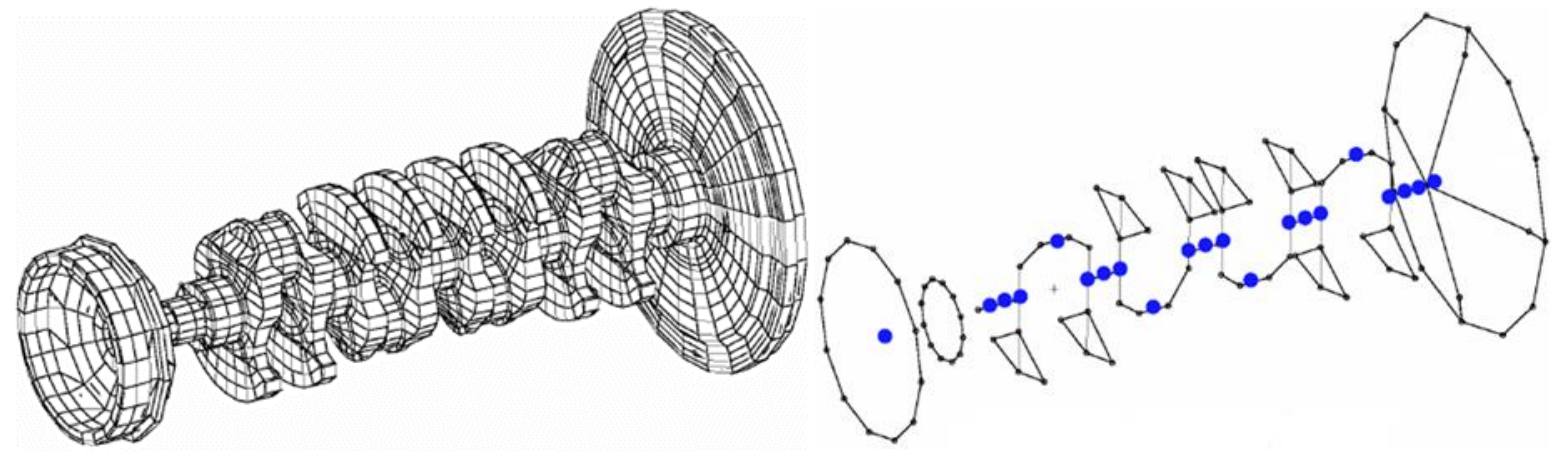

(a)

(b)

Figure 1. The schematic diagrams of the finite element model of a crankshaft of an in-line 4-cylinder engine and the main degree of freedom nodes model: (a) the schematic diagram of a finite element model of an in-line 4-cylinder engine crankshaft; (b) a schematic diagram of the main degree of freedom nodes model of the crankshaft of an in-line 4-cylinder engine after reduction.

The reduced crankshaft and block are imported into EXCITE software as elastic bodies for calculation. EXCITE is used for the calculation of multi-body dynamics and elastohydrodynamic lubrication calculation for main bearings. The calculation results of the main bearing lubrication are directly given by EXCITE. The stress of the crankshaft or block is obtained by the Direct data recovery process with the MSC Nastran Sol 109 method. In this study, it is assumed that only linear and elastic deformation of the crankshaft and block occur. The dynamic stiffness of the main bearing is obtained through multi-body dynamics calculations. In order to simplify the engine model, the main bearing cap and the main bearing wall are built as one model, ignoring the preload of the bolts of the main bearing caps. The finite element model diagram of the crankshaft and the block is shown in Figure 2, the block diagram of the calculation workflow is shown in Figure 3, and the dimensions of the crankshaft and block are shown in Table 1. 


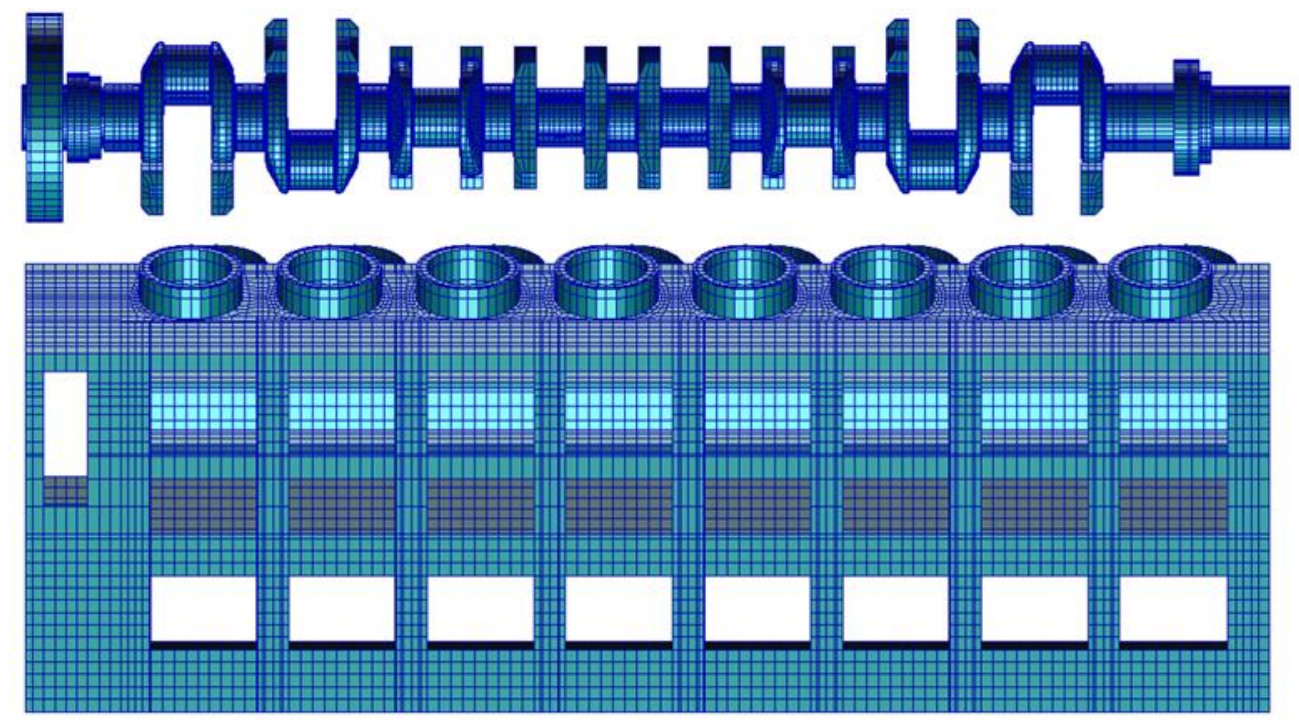

Figure 2. The diagram of the finite element model of the crankshaft and the block.

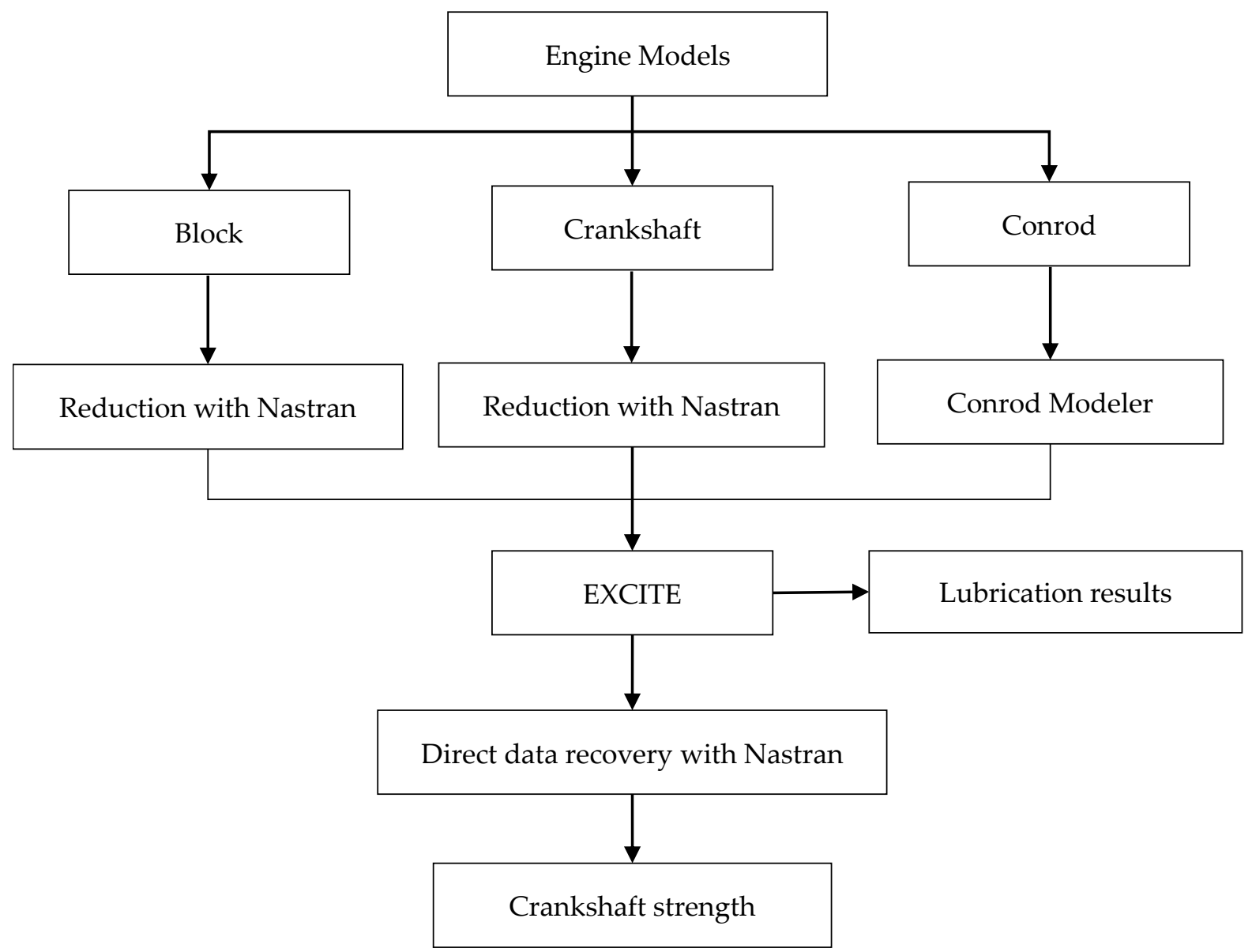

Figure 3. The block diagram of workflow of the anti-shock calculation model of the 16-cylinder V-type diesel engine. 
Table 1. The length, width, and height of the crankshaft and block.

\begin{tabular}{ccc}
\hline Item & Crankshaft & Block \\
\hline Length $(\mathrm{mm})$ & 3756 & 3594 \\
Width $(\mathrm{mm})$ & 672 & 1385 \\
Height $(\mathrm{mm})$ & 672 & 1288.2 \\
\hline
\end{tabular}

The 16-cylinder V-type diesel engine used in this research is a 4 stroke engine and has a mass of 22.6 tons, which exceeds the measurement range of a heavy impact machine. The impact experiments cannot be carried out on conventional impact machines. The method of calculation is used to analyze the anti-shock performance of the 16-cylinder V-type diesel engine. The main structure and performance parameters of the 16-cylinder V-type diesel engine are shown in Table 2.

Table 2. Main structure and performance parameters of the 16-cylinder V-type diesel engine.

\begin{tabular}{cc}
\hline Item & Parameter \\
\hline Type of engine layouts & V-type \\
Engine type & 4 stroke \\
Number of cylinders & 16 \\
Bore (mm) & 240 \\
Stroke $(\mathrm{mm})$ & 275 \\
Rated power $(\mathrm{kW})$ & 3240 \\
Dry weight $(\mathrm{kg})$ & 22,600 \\
Rated speed $(\mathrm{r} / \mathrm{min})$ & 1000 \\
Over 10\% speed (r/min) & 1100 \\
Mean effective pressure (MPa) & 1.82 \\
Maximum blast pressure (MPa) & 13.37 \\
\hline
\end{tabular}

The schematic diagram of the anti-shock calculation model of the 16-cylinder V-type diesel engine by EXCITE is shown in Figure 4. Figure 4 shows the logical connection between the components in the EXCITE model. The model includes crankshaft, block, piston, connecting rod, etc. In EXCITE software, the basic information of the diesel engine, such as the data in Table 2, needs to be filled; the gas explosion pressure data are submitted; the basic data of the crankshaft, block, connecting rod, and piston are set; and the simulation control parameters, result control parameters, etc., are set up. According to early researchers' conclusions [6-9], the crankshaft is a component that needs to be focused on in external impact. This study focuses on the crankshaft. The crankshaft and engine block are created by finite element modeling and imported to EXCITE and set as elastic body to consider the influence of the forced deformation of the crankshaft and the main bearing under the oil film pressure. Pistons and connecting rods are not the focus of this study and are established in a simplified model.

The main bearing is the focus of the research, and the elastohydrodynamic lubrication method is used in the main bearing lubrication calculation. The Greenwood-Tripp asperity contact model is used to calculate the contact friction that may occur in lubrication. In order to reduce the calculation amount of the model, a nonlinear spring damping model is used to simulate the big end bearing of the connecting rod. The length of the nonlinear spring is the radial clearance of the big end bearing. At zero displacement position, the nonlinear spring has a small stiffness and damping, at the radial clearance position, the nonlinear spring has a large stiffness and damping.

The 9 main bearings are numbered from 1 to 9 from the free end of the diesel engine to the output end. Some main bearing structure and lubrication parameters used in the calculation are shown in Table 3. 


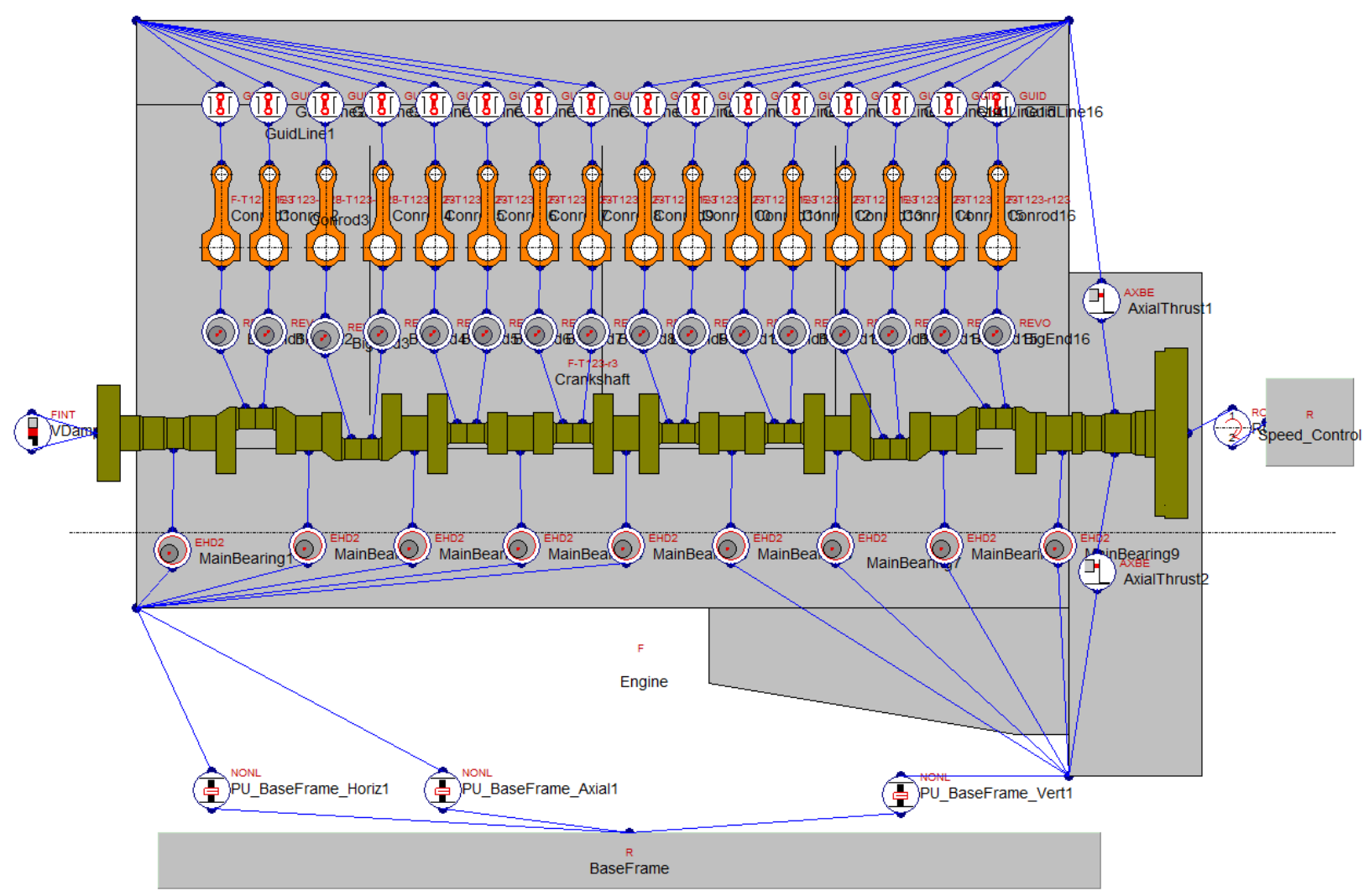

Figure 4. The schematic diagram of the anti-shock calculation model of the 16-cylinder V-type diesel engine.

Table 3. Specifications of the main bearings.

\begin{tabular}{cc}
\hline Item & Parameters \\
\hline Main bearing width $(\mathrm{mm})$ & 83 (No. 1 Bearing) \\
Main journal diameter $(\mathrm{mm})$ & 90 (No. 2-8 Bearing) \\
Main bearing radial clearance $(\mathrm{mm})$ & 88 (No. 9 Bearing) \\
Groove width on upper bearing bush $(\mathrm{mm})$ & 220 \\
Diameter of bore on main journal $(\mathrm{mm})$ & 0.125 \\
Oil type & 22 \\
Kinematic oil viscosity at $100{ }^{\circ} \mathrm{C}\left(\mathrm{mm}^{2} / \mathrm{s}\right)$ & 20 \\
Kinematic oil viscosity at $40^{\circ} \mathrm{C}\left(\mathrm{mm}^{2} / \mathrm{s}\right)$ & 14.7 \\
Oil density $\left(\mathrm{Kg} / \mathrm{m}^{3}\right)$ & 896.2 \\
Oil temperature $\left({ }^{\circ} \mathrm{C}\right)$ & 88 \\
Lubrication oil supply pressure $(\mathrm{MPa})$ & 0.49 \\
Surface roughness of main journal $\mathrm{Rrms}(\mu \mathrm{m})$ & 0.5 \\
Surface roughness of main bearing bush $\mathrm{Rrms}(\mu \mathrm{m})$ & 1 \\
\hline
\end{tabular}

\subsection{Boundary Conditions}

The firing sequence and interval angle of the gas are set according to the actual conditions of the diesel engine. The gas explosion pressure uses the measured data and is made into a dat format file, which contains the gas explosion pressure value of a complete working cycle. The dat file contains two columns, the first column is time, the unit is crankshaft angle, the second column is gas explosion pressure, and the unit is MPa. EXCITE software reads this dat file and assigns the gas explosion pressure to the main degree of freedom nodes of the pistons in the load data table. In the subsequent calculation process, the EXCITE software will automatically load the gas explosion pressure at the corresponding time on the corresponding main degree of freedom nodes of the pistons. 
The gas explosion pressure is transmitted to the block through the pistons, the connecting rods, and the crankshaft.

The external shock load uses experiment data, as shown in Figure 5. The x-axis is time and the unit is seconds, and the y-axis is shock displacement and the unit is $\mathrm{mm}$. The external shock load is the vertical shock displacement of diesel engine foundation and is saved in a dat format file. The dat file contains two columns of data. The first column is the time in seconds, and the second column is the impact displacement in $\mathrm{mm}$. The dat file is imported into the EXCITE software. In EXCITE, the diesel engine foundation is specified to move according to the impact displacement in the dat file. The foundation of the diesel engine had no movement in other directions except for the vertical direction. There are no other constraints on the engine block except for the shock absorbers. The engine block is driven by the shock absorbers and vibrates with the vertical displacement movement of the foundation. In order to simplify the calculation model, this research assumes that the foundation is a rigid body. However, the length of this diesel engine is more than $3600 \mathrm{~mm}$, and the installation location is in the naval engine room. Due to the long length of the diesel engine, the influence of the elasticity of the foundation should be taken into consideration, and the influence of this factor will be added in the future research.

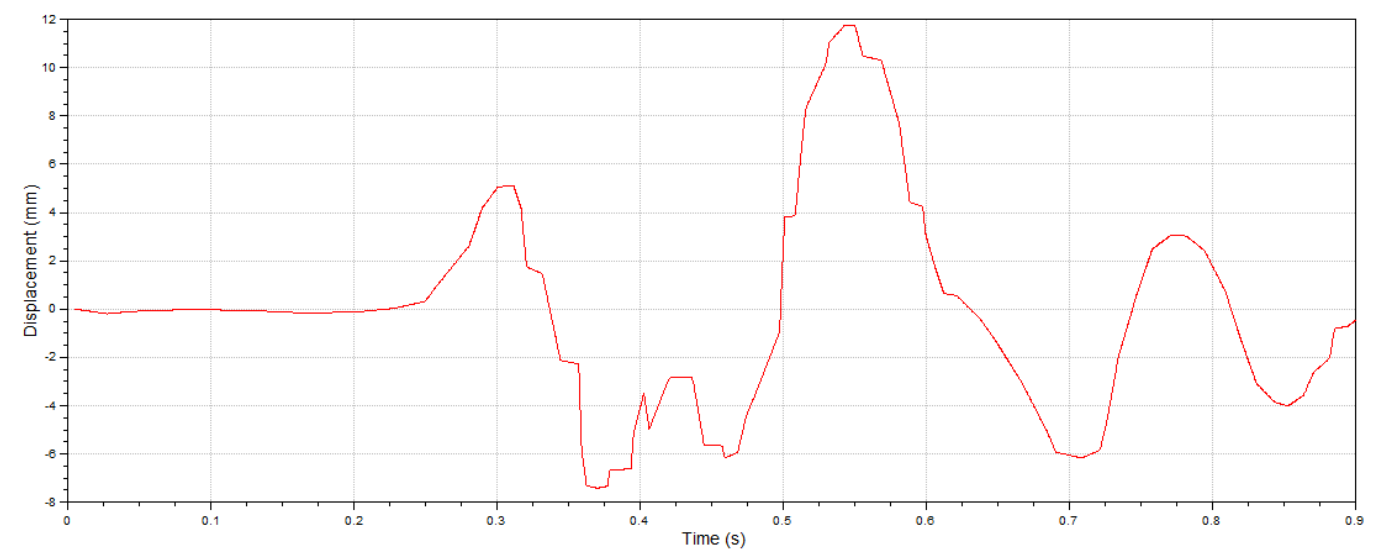

Figure 5. The external shock load of the 16-cylinder V-type diesel engine.

In this study, both the engine block and the crankshaft are assumed to be linear elastic bodies. The dynamic characteristics of the engine block and crankshaft are preserved in the reduction, the response of block and crankshaft to gas explosion pressure, inertial force, and external shock load is calculated.

The vertical shock is the main part of underwater explosion load applied to the navy ship and the main part of shock damage of shipboard equipment [59]. This research mainly focuses on the vertical response of the diesel engine under external shock. In order to make external impact energy to act in the vertical direction as much as possible and to obtain the highest vertical impact response, shock absorbers with regular stiffness are installed on the vertical direction and shock absorbers with large stiffness are installed on the horizontal and longitudinal direction of the diesel engine. The vertical, horizontal, and longitudinal shock absorbers are installed on both sides of the diesel engine on the first, third, fifth, seventh, and ninth main bearing walls. The parameters of vertical, horizontal, and longitudinal shock absorbers are shown in Table 4. To simplify the calculation model, the shock absorbers are not modelled with frequency-dependent stiffness-damping. The shock load tends to excite a wide spectrum of frequencies, impact damage is usually caused by low frequency part of the external shock, and the shock absorber is mainly used to suppress low-frequency vibration. 
Table 4. Specifications of the shock absorbers.

\begin{tabular}{ccc}
\hline Item & Stiffness (kN/mm) & Damping (Ns/mm) \\
\hline vertical shock absorber & 15 & 4 \\
horizontal shock absorber & 4000 & 4 \\
longitudinal shock absorber & 4000 & 4 \\
\hline
\end{tabular}

The diesel engine anti-shock performance calculation results are mainly evaluated by two types of indicators. One is the diesel engine main bearing lubrication results, such as oil film pressure, asperity contact pressure and minimum oil film thickness. The other is the crankshaft stress.

\subsection{Key Parameters for Elastohydrodynamic Lubrication Algorithm in External Shock Condition}

The external shock is equivalent to the interference on the elastohydrodynamic lubrication calculation. Whether the elastohydrodynamic lubrication algorithm can complete the calculation under interference is the key to the study. The calculation step size and the iterations number have an important influence on the completion of the calculation. Both EXCITE software and elastohydrodynamic lubrication algorithms are designed for calculations under normal operating conditions of diesel engines. Under external shock conditions, the simulation step size and the maximum iterations number need to be adjusted.

In order to ensure that the iterative calculation can converge, a very small simulation step size and a high number of iterations are required. The smaller the calculation step size, the easier the calculation will converge, but the overall calculation time becomes longer. The initial simulation step size is reduced from $0.0625^{\circ} \mathrm{CA}$ (crankshaft angle) in normal conditions to $0.0078125^{\circ} \mathrm{CA}$ in shock conditions, the minimum step size is reduced from $0.0078125^{\circ} \mathrm{CA}$ in normal conditions to $1 \mathrm{e}-5^{\circ} \mathrm{CA}$ in shock conditions.

EXCITE is an iterative calculation software. The meaning of the maximum iterations number is that when the iterative calculation reaches this value, if the accuracy requirement is not met, the result of the last calculation is retained, the iteration is stopped, and the calculation of the next time step size is performed. Under external shocks, the calculation of elastohydrodynamic lubrication is not easy to converge, so the maximum iterations number of 800 used in normal operating conditions is not enough for external shock conditions. The maximum number of iterations is increased from 800 in normal conditions to 10,000 in shock conditions.

Decreasing the simulation step size and increasing the number of iterations will significantly increase the calculation time. When the main bearing adopts the spring damping model, the calculation time in the impact environment is $5-16 \mathrm{~h}$. When the main bearing adopts the elastohydrodynamic lubrication model, the calculation time in the impact environment is 40 to $90 \mathrm{~h}$.

Joint parameters that can work normally under normal conditions may fail under external impact conditions. In this study, a calculation error report was encountered, the distance was too large at a main degree of freedom node of the thrust bearing. The thrust bearing works normally under normal working conditions. After analysis, it is found that the stiffness of the thrust bearing is selected according to the normal working environment and the stiffness value is small. In shock conditions, the external shock will excite the threedimensional vibration of the diesel engine, the stiffness value of the thrust bearing is not sufficient to restrain the longitudinal vibration of the crankshaft, resulting in the excessive displacement at a main degrees of freedom node of the thrust bearing. After increasing the stiffness of the thrust bearing from $10,000 \mathrm{~N} / \mathrm{mm}$ to $12,000 \mathrm{~N} / \mathrm{mm}$, the calculation of elastohydrodynamic lubrication in the impact environment can be successfully completed.

By reducing the calculation step size, increasing the iterations number, and increasing the stiffness of the thrust bearing, the elastohydrodynamic lubrication calculation under the impact environment can be successfully completed. 


\section{Case Study}

\subsection{Comparison of Calculation and Experiment}

The vertical acceleration of the diesel engine feet obtained by calculation is shown in Figure 6, wherein the x-axis is time, the unit is seconds, the y-axis is acceleration, and the unit is gravitational acceleration g. Figure $6 \mathrm{a}$ is the acceleration result of diesel engine feet in $0-0.9 \mathrm{~s}$, and the acceleration amplitude decays with time due to damping. The EXCITE algorithm is an iterative calculation affected by the initial value and has a gradual convergence process. The results of very high acceleration at $0 \mathrm{~s}$ in Figure $6 \mathrm{a}$ is the numerical abnormalities caused by the initial value. Figure $6 \mathrm{~b}$ is the acceleration result of the diesel engine feet in $0.5-0.9 \mathrm{~s}$; it can be seen from Figure $6 \mathrm{~b}$ that within 0.5 to $0.9 \mathrm{~s}$, the acceleration amplitude is mainly distributed between $-8 \mathrm{~g}$ and $8 \mathrm{~g}$ and the acceleration amplitude decays with time due to damping. The acceleration signal is composed of low-frequency vibration components and high-frequency vibration components. The low-frequency vibration components mainly refer to the large fluctuation period in the acceleration curve, which is mainly caused by the external shock applied to the diesel engine body through the shock absorber. The high-frequency vibration component mainly refers to the dense vibration signal parts on the acceleration curve, which is caused by the high-frequency periodic excitation, such as gas explosion pressure, the exciting force of the valve system, and the inertial force of the crankshaft, connecting rod, and piston.

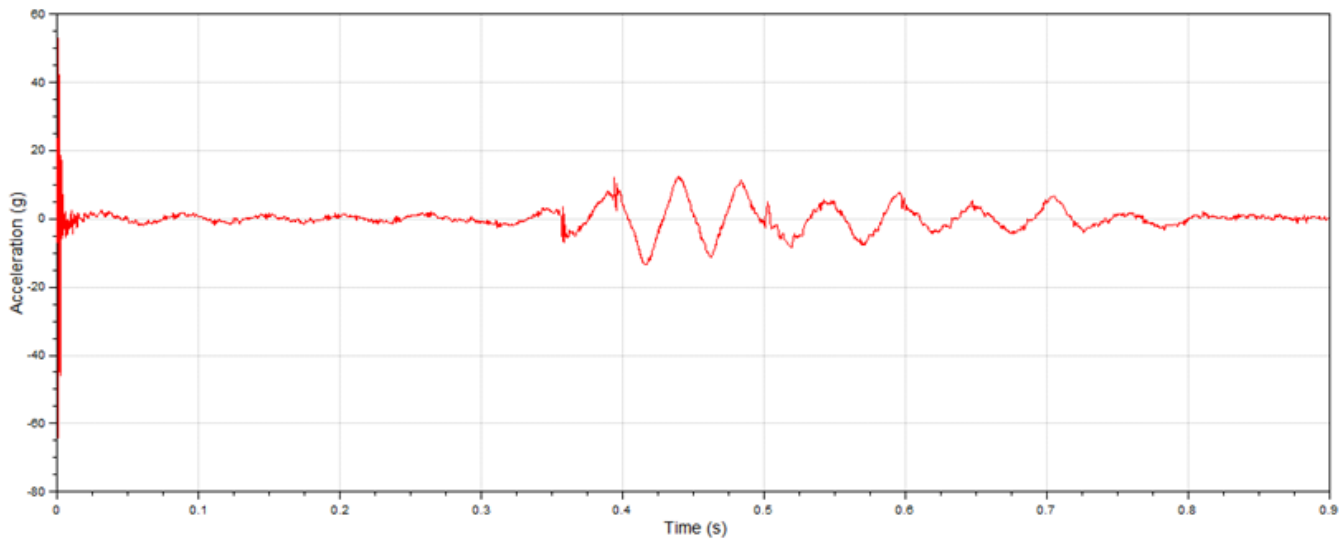

(a)

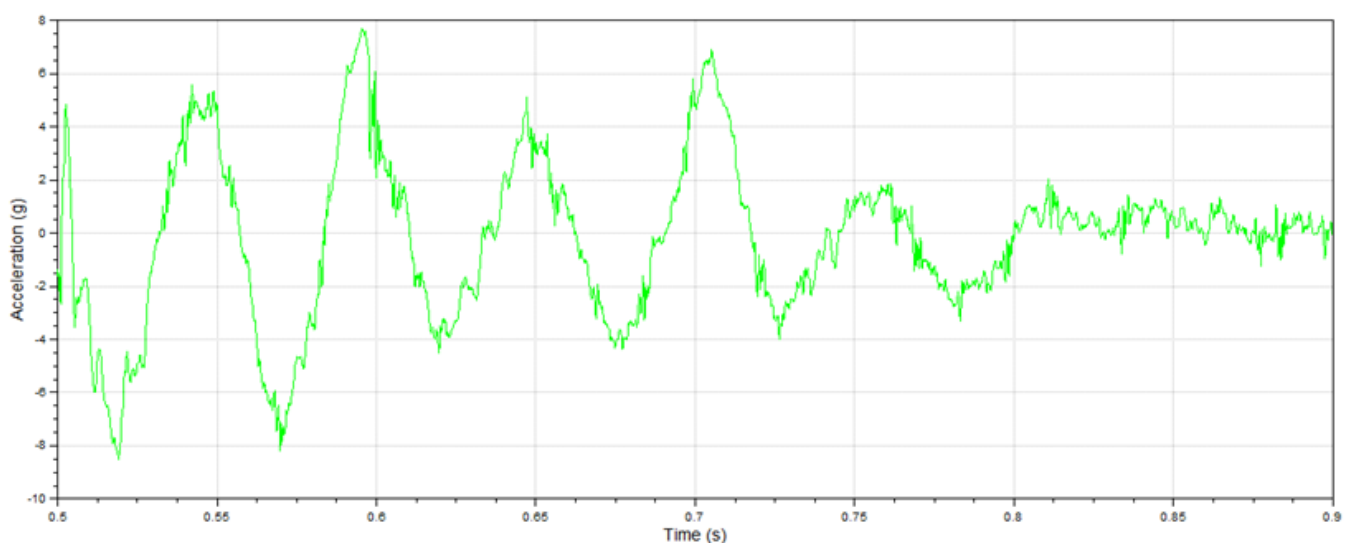

(b)

Figure 6. The calculation results on vertical acceleration of the diesel engine feet. (a) The calculation results on vertical acceleration of the diesel engine feet in 0-0.9 s. (b) The calculation results on vertical acceleration of the diesel engine feet in 0.5 to $0.9 \mathrm{~s}$.

Figure 7 shows the comparison between the calculation results and the experiment results of the acceleration at the diesel engine feet. The red curve in Figure 7 is the 
calculation result and the dark blue curve is the experiment result. It can be seen from Figure 7 that the experiment acceleration amplitude is mainly distributed between $-5 \mathrm{~g}$ and $5 \mathrm{~g}$ and decays with time due to damping. In $0.5-0.9 \mathrm{~s}$, the experiment curve lasted for about seven cycles. The calculated acceleration amplitude is mainly distributed between $-8 \mathrm{~g}$ and $8 \mathrm{~g}$ and decays with time due to damping. In $0.5-0.9 \mathrm{~s}$, the calculation curve lasted for about eight cycles. The calculated result has a similar trend with the experimental result and has a difference in acceleration amplitude and vibration frequency with the experimental result. The reason for the difference, on the one hand, may be that the calculation modeling is not accurate enough; on the other hand, the calculation parameters may be incorrectly selected, resulting in large errors in the results. The calculation model can be used to predict the diesel engine response trend in the external impact condition and can be used as an alternative to the impact test.

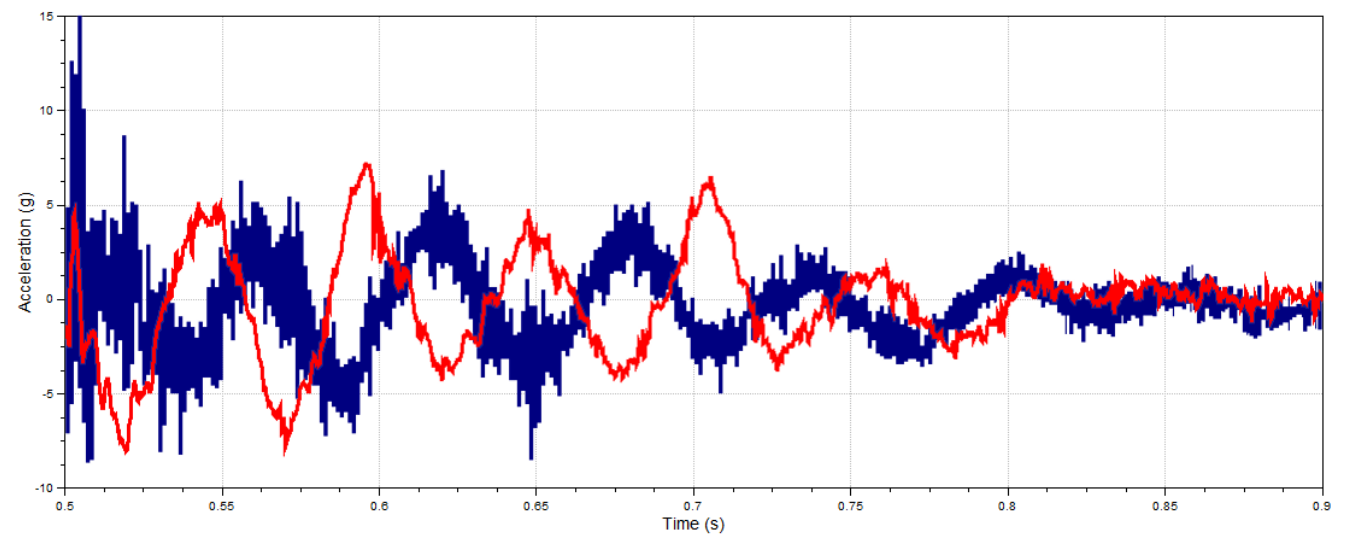

Figure 7. The contrast between diesel engine calculation results (red curve) and test result (dark blue curve) on vertical acceleration of the diesel engine feet.

\subsection{Calculation of Diesel Engine with Shock Absorbers in Normal Condition}

There are two installation methods for navy diesel engines on ships, namely elastic installation (with shock absorbers) and rigid installation (without shock absorbers). This section will calculate the 16-cylinder V-type diesel engine with shock absorbers in normal condition (without external shock). The calculation results mainly focus on the results of main bearing lubrication and crankshaft stress.

\subsubsection{Main Bearing Lubrication of Diesel Engine with Shock Absorbers in} Normal Condition

According to the evaluation point of the AVL company for the high-grade bearing bush of civil vehicle engine, the peak oil film pressure in the bearing lubrication calculation results of the EXCITE software should be less than 100-150 MPa, the peak asperity contact pressure should be less than $50 \mathrm{MPa}$, and the minimum oil film thickness should be greater than $1.5 \mu \mathrm{m}$; for the bearing to work normally [60]. With the AVL evaluation method, the three indicators of peak oil film pressure, peak asperity contact pressure, and minimum oil film thickness are used as the basis for the main bearing lubrication evaluation. Table 5 lists the value of the maximum of peak oil film pressure, the maximum of peak asperity contact pressure, and the minimum value of the minimum oil film thickness of the 9 main bearings in the time range of 0-0.9 s under normal conditions of a 16-cylinder V-type diesel engine.

It can be seen from Table 5 that, according to the above evaluation point of the AVL Company for the peak oil film pressure index, each main bearing meets the requirement that the peak oil film pressure is less than 100-150 MPa in normal conditions.

Evaluated by the peak asperity contact pressure index, each main bearing meets the requirement that the peak asperity contact pressure is less than $50 \mathrm{MPa}$ in normal conditions. 
Table 5. Lubrication calculation results of diesel engine in normal conditions.

\begin{tabular}{cccc}
\hline Main Bearing & Peak Oil Film Pressure (MPa) & $\begin{array}{c}\text { Peak Asperity Contact } \\
\text { Pressure (MPa) }\end{array}$ & $\begin{array}{c}\text { Minimum Oil Film } \\
\text { Thickness }(\mu \mathrm{m})\end{array}$ \\
\hline 1 & 61.166 & $5.044 \times 10^{-7}$ & 4.2 \\
2 & 57.338 & 14.816 & 1.065 \\
3 & 53.517 & 0 & 4.693 \\
4 & 61.874 & $8.561 \times 10^{-2}$ & 2.875 \\
5 & 56.926 & $1.469 \times 10^{-3}$ & 3.593 \\
6 & 55.082 & $1.447 \times 10^{-4}$ & 3.847 \\
8 & 63.852 & $9.141 \times 10^{-3}$ & 3.322 \\
9 & 56.472 & 1.175 & 2.125 \\
\end{tabular}

Using the minimum oil film thickness index to evaluate, it can be found that there is a case where the minimum oil film thickness does not meet the requirement to be greater than $1.5 \mu \mathrm{m}$, the $1.065 \mu \mathrm{m}$ of the second main bearing under normal condition. The second main bearing is in poor working condition. Based on the values in the AVL company's evaluation point, the minimum oil film thickness values in the above cases are not up to the recommended values.

Shukuan Mou pointed out that, when calculating the bearing lubrication, the surface roughness of the main journal and the main bearing bush is taken according to the machining process parameters. It is the "nominal" roughness which reflects the surface conditions before running-in. In the actual environment, the influence of running-in on the surface roughness should be considered. After proper running-in, the surface roughness of the journal and the bearing bush is improved, and the minimum oil film thickness can be as small as the half of the sum of the surface roughness of the journal and the bearing bush, but the continuous angle cannot exceed $20 \%$ of the entire working cycle. This is a semi-dry friction state, and the bearing may still work normally [61].

The calculated surface roughness of the main journal of the 16-cylinder V-type diesel engine is $0.5 \mu \mathrm{m}$, the surface roughness of the main bearing bush is $1 \mu \mathrm{m}$, and the half of the sum is $0.75 \mu \mathrm{m}$. It can be seen from Table 5 that the minimum oil film thickness of all main bearings exceeds $0.75 \mu \mathrm{m}$. Next, the continuous angle of the relevant main bearing in a semi-dry friction state needs to investigate. The continuous time should not exceed $20 \%$ of the entire working cycle, which is $0.024 \mathrm{~s}$ in this research.

As shown in Figure 8, it is the minimum oil film thickness curve of the second main bearing in $0-0.9 \mathrm{~s}$ in normal conditions. In Figure 8, the $\mathrm{x}$-axis represents time in seconds, and the y-axis represents the minimum oil film thickness in microns. The EXCITE calculation algorithm is an iterative calculation, is affected by the initial value, and has a gradual convergence process. The result of the very high minimum oil film thickness at $0 \mathrm{~s}$ in Figure 8 is the numerical abnormalities caused by the initial value. Among them, at $0.03875 \mathrm{~s}$, the minimum oil film thickness is $1.065 \mu \mathrm{m}$. It can be found from the calculation results that when the minimum oil film thickness is less than $1.5 \mu \mathrm{m}$, it lasts from $0.0386706 \mathrm{~s}$ to $0.0388294 \mathrm{~s}$, which lasts $0.0001588 \mathrm{~s}$ and is much lower than $20 \%$ of the entire working cycle (which is $0.024 \mathrm{~s}$ ). Therefore, according to the evaluation criteria in Reference [61], the second main bearing under normal conditions can work normally.

In normal conditions, among the nine main bearings, the second main bearing has the minimum oil film thickness and is in poor working condition. Figure 9a is the distribution map of the average oil film pressure of the second main bearing in $0-0.12 \mathrm{~s}$ in normal conditions. The $\mathrm{x}$-axis represents the circumferential length of the inner surface of the main bearing bush, expressed in a circumferential angle of $0^{\circ}$ to $360^{\circ}$. Taking the vertical direction of the upper bearing bush as the starting position $0^{\circ}$, the range of $0^{\circ}$ to $90^{\circ}$ and $270^{\circ}$ to $360^{\circ}$ is the upper bush, and the range of $90^{\circ}$ to $270^{\circ}$ is the lower bush. The y-axis represents the width of the bearing bush. The high oil film pressure distribution area on the bearing bush (the red, yellow, and green colors in Figure 9a) is concentrated near the 
center of the lower bush at $180^{\circ}$. It can also be seen that the distribution area of the high oil film pressure is wide, which is beneficial for the main journal to obtain a good oil film support in a wide angle of the lower bearing bush.

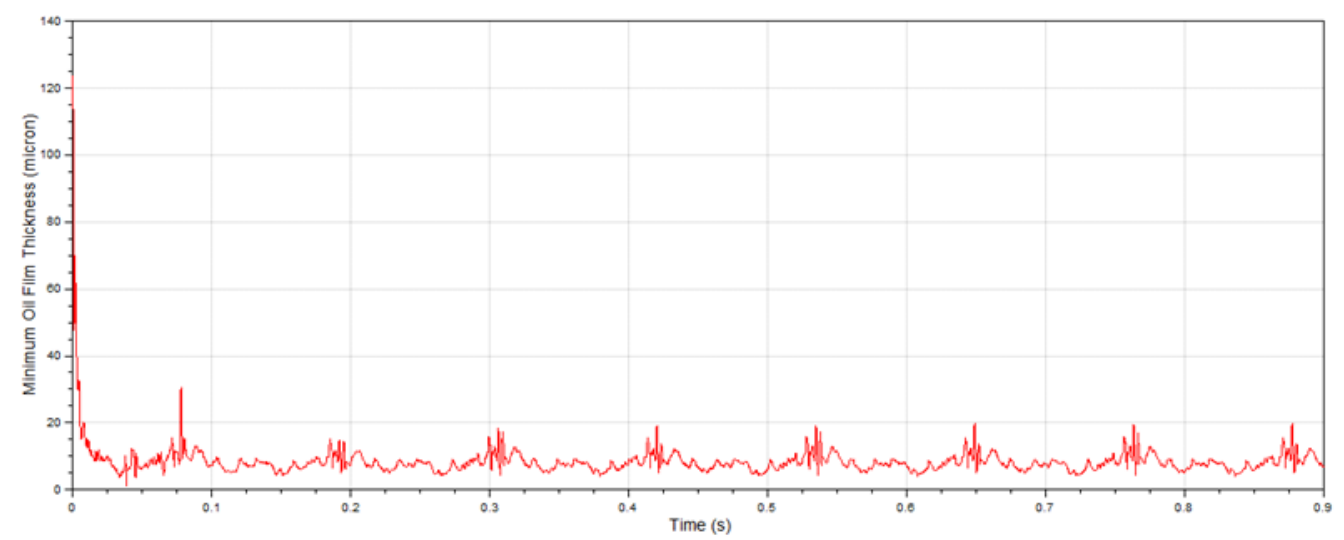

Figure 8. The minimum oil film thickness curve of the second main bearing under normal conditions.

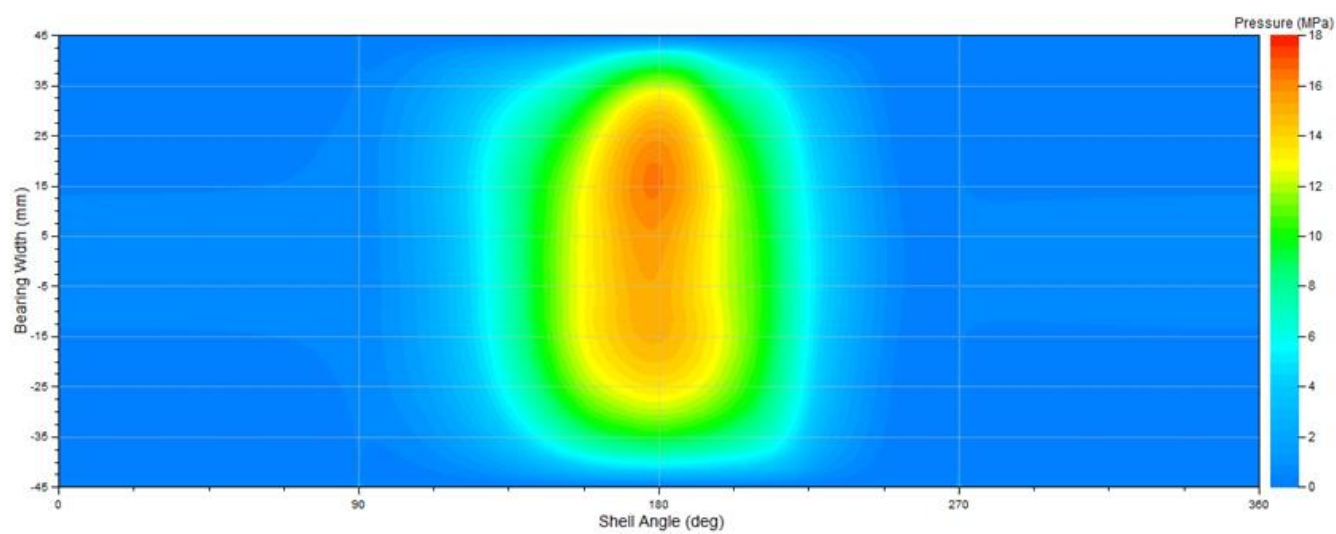

(a)

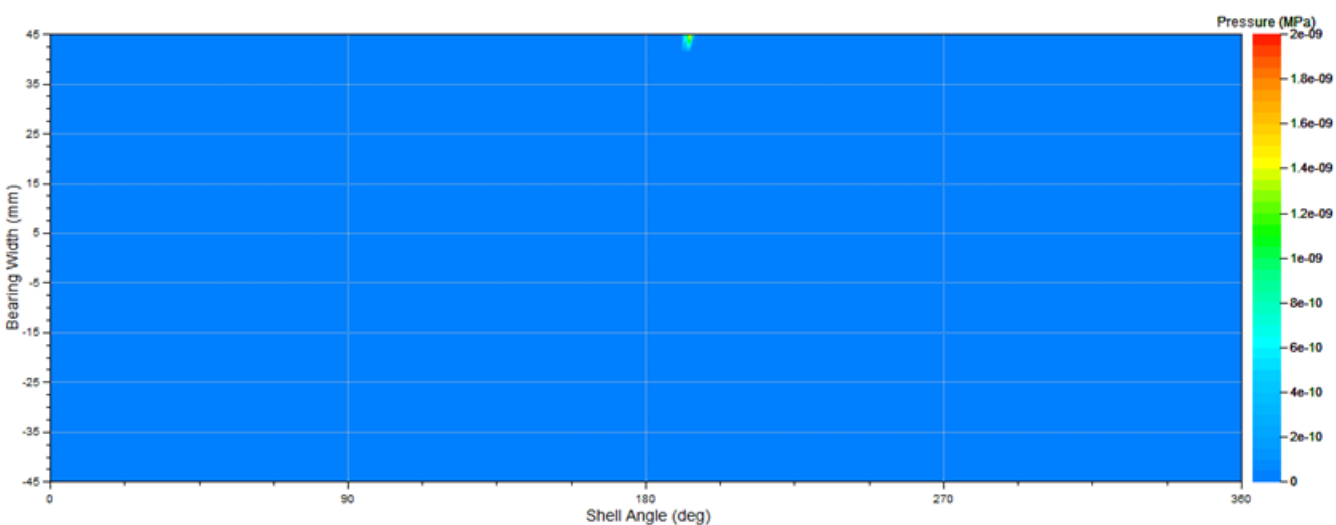

(b)

Figure 9. Distribution map of the average oil film pressure and the average asperity contact pressure of the second main bearing in normal condition in 0 to $0.12 \mathrm{~s}$. (a) Distribution map of the average oil film pressure of the second main bearing. (b) Distribution map of the average asperity contact pressure of the second main bearing.

Figure $9 \mathrm{~b}$ shows the average asperity contact pressure distribution map of the second main bearing in $0-0.12 \mathrm{~s}$ in normal conditions. The $\mathrm{x}$-axis represents the circumferential length of the bearing bush, and the y-axis represents the width of the bearing bush. The small green color zone in the Figure $9 \mathrm{~b}$ represents the area where asperity contact occurs, 
which only accounts for a very small proportion of the entire bearing bush area. The asperity contact position of the second main bearing is at the edge of the bearing shell near the $180^{\circ}$ position of the lower bush.

It can be seen from Figure 9 that the working state of the second main bearing is in safe condition.

Integrating the evaluation points of the AVL company and reference [61], the peak oil film pressures of the nine main bearings are less than 100-150 MPa; the peak asperity contact pressures of the nine main bearings are less than $50 \mathrm{MPa}$. Although the minimum oil film thickness is lower than $1.5 \mu \mathrm{m}$ in one case, it still exceeds half of the sum of the roughness of the main journal and the main bearing, and the continuation time is much lower than $20 \%$ of the entire working cycle. So, it can be concluded that the main bearings of the 16-cylinder V-type diesel engine can work normally in normal conditions.

\subsubsection{Crankshaft Stress of Diesel Engine with Shock Absorbers in Normal Conditions}

As shown in Figure 10, it is the peak crankshaft stress curve in normal conditions within 0 to $0.9 \mathrm{~s}$. The stress value in any time in Figure 10 represents the maximum value of the entire crankshaft at that moment, and the peak crankshaft stress curve is used to reflect the trend of the crankshaft stress over time. In Figure 10, it can be noticed that between 0 and $0.05 \mathrm{~s}$, there are two peak crankshaft stresses, $432 \mathrm{MPa}$ and $442 \mathrm{MPa}$, which are significantly higher than the peak crankshaft stress within 0.05-0.9 s. Under normal operating conditions, the stress state of the crankshaft is periodic in each working cycle. In $0-0.9 \mathrm{~s}$, nearly eight working cycles are calculated. The two higher crankshaft stresses within $0-0.05 \mathrm{~s}$ only appeared at the beginning of the calculation, did not appear again in the subsequent calculation results. Furthermore, EXCITE calculation is an iterative calculation, which will be affected by the initial value, and there is a process in which the simulation iteration gradually converges. Considering that these two higher crankshaft stresses in 0-0.05 s may be abnormal results caused by insufficient convergence in the initial stage of simulation, they are not used in the analysis of crankshaft stress results.

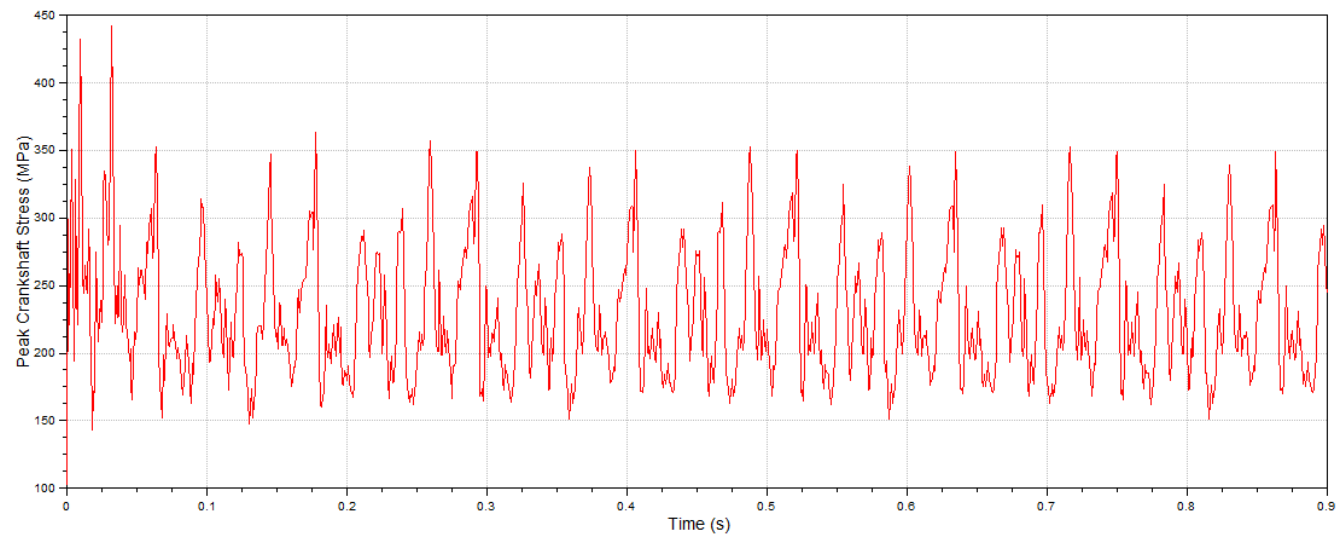

Figure 10. Peak crankshaft stress curve under normal condition within 0 to $0.9 \mathrm{~s}$. The $\mathrm{x}$-axis represents the time in seconds, and the $\mathrm{y}$-axis represents the peak crankshaft stress in MPa.

Within $0.05-0.9 \mathrm{~s}$, the maximum crankshaft stress in impact conditions is $364 \mathrm{MPa}$ at $0.177937 \mathrm{~s}$ at the eighth crank pin, as shown in Figure 11. That does not exceed the yield limit of the crankshaft material $(650 \mathrm{MPa})$ with a large safety margin. 


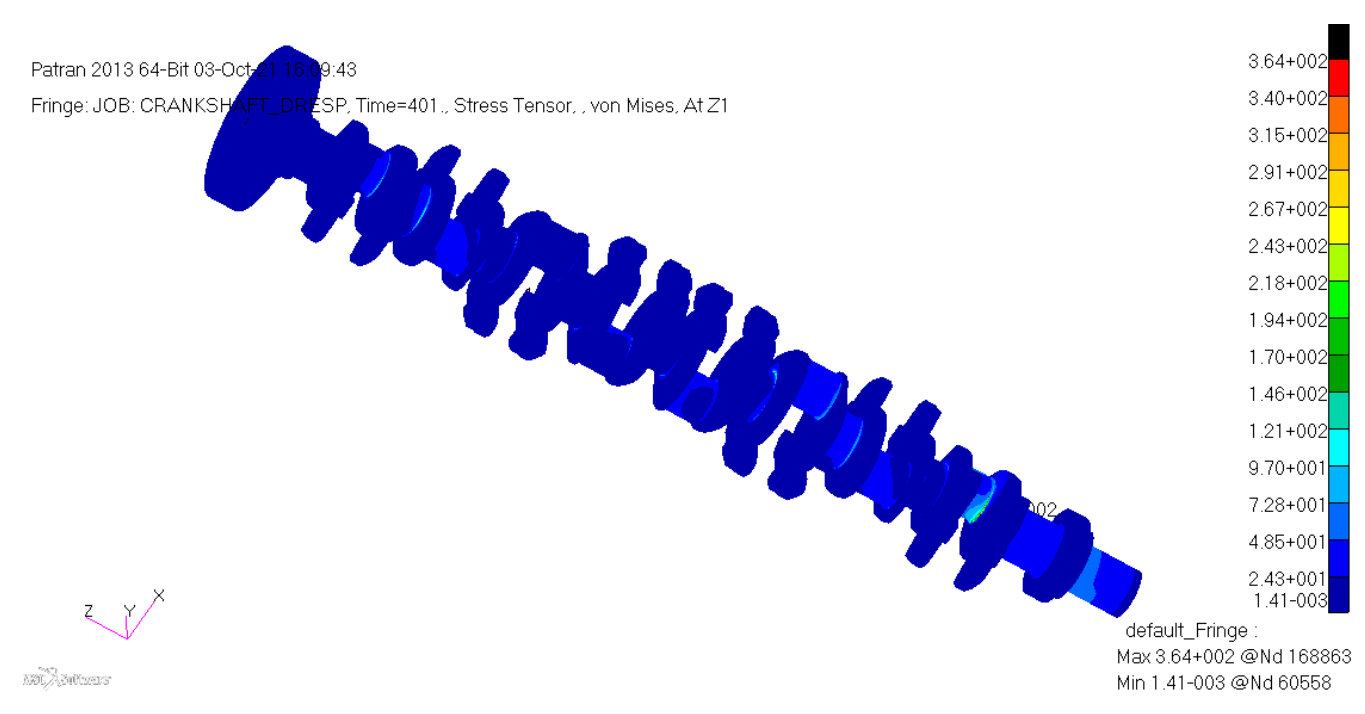

Figure 11. Under normal conditions, the maximum crankshaft stress is $364 \mathrm{MPa}$ at $0.177937 \mathrm{~s}$, which is located at the eighth crank pin.

In short, in $0-0.9 \mathrm{~s}$, the crankshaft stress in impact conditions does not exceed the yield limit of the crankshaft material with a large safety margin, so the crankshaft of the diesel engine with a shock absorber is safe under normal conditions.

Through the calculation, it can be found that the main bearing can maintain the normal lubrication state, and the crankshaft stress does not exceed the yield limit, so the diesel engine with shock absorbers can work normally in the normal condition.

\subsection{Calculation of Diesel Engine with Shock Absorbers in Impact Condition}

This section will simulate the 16-cylinder V-type diesel engine with shock absorbers in external shock condition. The calculation results mainly focus on the results of main bearing lubrication and crankshaft stress. The external impact is from the experimental data and loaded on the diesel engine base.

3.3.1. Main Bearing Lubrication of Diesel Engine with Shock Absorbers in Impact Condition

Table 6 lists the value of the maximum of peak oil film pressure, the maximum of peak asperity contact pressure, and the minimum value of the minimum oil film thickness of the nine main bearings in the time range of $0-0.9 \mathrm{~s}$ under external impact conditions of the 16-cylinder V-type diesel engine.

Table 6. Lubrication calculation results of diesel engine with shock absorbers in external shock conditions.

\begin{tabular}{cccc}
\hline Main Bearing & Peak Oil Film Pressure (MPa) & $\begin{array}{c}\text { Peak Asperity Contact } \\
\text { Pressure (MPa) }\end{array}$ & $\begin{array}{c}\text { Minimum Oil Film } \\
\text { Thickness }(\mu \mathrm{m})\end{array}$ \\
\hline 1 & 66.984 & 5.773 & 4.083 \\
2 & 57.195 & 14.372 & 1.081 \\
3 & 55.74 & 0 & 4.759 \\
4 & 62.114 & $8.273 \times 10^{-2}$ & 2.883 \\
5 & 59.696 & $4.693 \times 10^{-3}$ & 3.43 \\
6 & 56.478 & $1.97 \times 10^{-4}$ & 3.818 \\
7 & 80.243 & 0.864 & 2.229 \\
8 & 59.023 & 1.808 & 1.971 \\
9 & 64.28 & 11.677 & 1.093 \\
\hline
\end{tabular}

It can be seen from Table 6 that, according to the evaluation point of the AVL Company for the peak oil film pressure index, each main bearing meets the requirement that the 
peak oil film pressure is less than 100-150 MPa in external shock conditions. Evaluated by the peak asperity contact pressure index, each main bearing meets the requirement that the peak asperity contact pressure is less than $50 \mathrm{MPa}$ in external shock conditions. Using the minimum oil film thickness index to evaluate, it can be found that there are two cases where the minimum oil film thickness does not meet the requirement (to be greater than $1.5 \mu \mathrm{m}$ ), the $1.081 \mu \mathrm{m}$ of the second main bearing, and the $1.093 \mu \mathrm{m}$ of the ninth main bearing under impact conditions. Based on the values in the AVL company's evaluation point, the minimum oil film thickness values in the above two cases are not up to the requirements.

According to the evaluation criteria in Reference [61], as shown in Figure 12, it is the minimum oil film thickness curve of the second main bearing in 0-0.9 $\mathrm{s}$ in impact conditions. Among them, at $0.03875 \mathrm{~s}$, the minimum oil film thickness is $1.081 \mu \mathrm{m}$. It can be found from the calculation results that when the minimum oil film thickness is less than $1.5 \mu \mathrm{m}$, it lasts from $0.0386706 \mathrm{~s}$ to $0.0388294 \mathrm{~s}$, which lasts $0.0001588 \mathrm{~s}$ and is much lower than $20 \%$ of the entire working cycle (which is $0.024 \mathrm{~s}$ ).

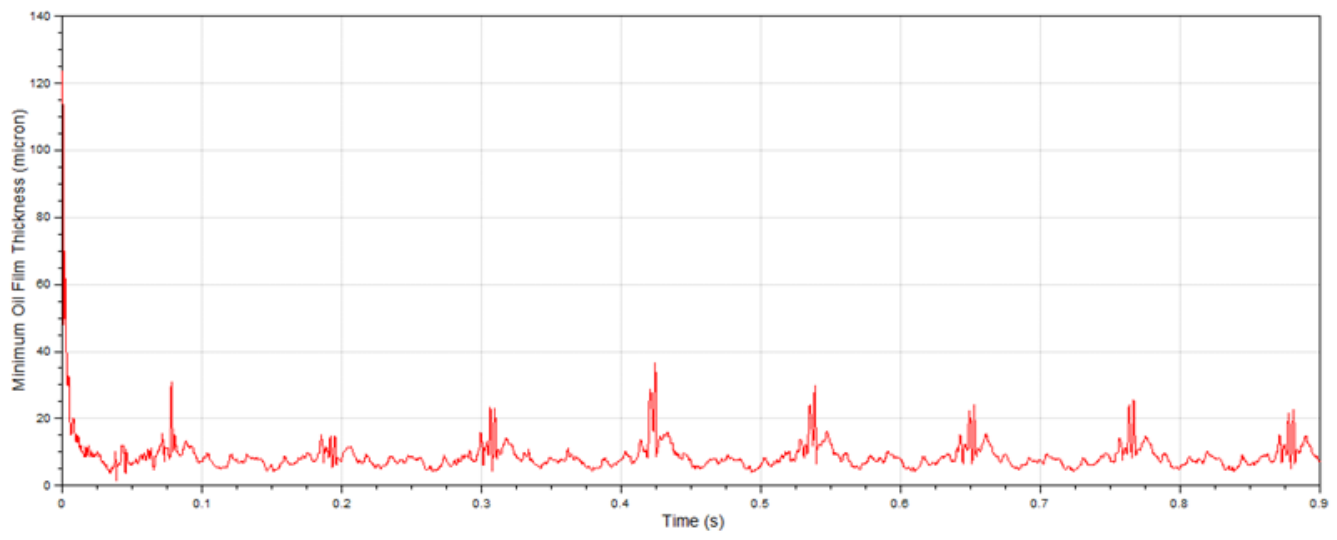

Figure 12. The minimum oil film thickness curve of the second main bearing under impact condition.

As shown in Figure 13, it is the minimum oil film thickness curve of the ninth main bearing in $0-0.9 \mathrm{~s}$ in the impact condition, where at $0.6936 \mathrm{~s}$, the minimum oil film thickness is $1.093 \mu \mathrm{m}$. It can be found from Figure 13 that when the minimum oil film thickness is less than $1.5 \mu \mathrm{m}$, it lasts from $0.692798 \mathrm{~s}$ to $0.694385 \mathrm{~s}$, which lasts for $0.001587 \mathrm{~s}$ and is much lower than $20 \%$ of the entire working cycle (that is $0.024 \mathrm{~s}$ ). Therefore, according to the evaluation criteria in Reference [61], the second and ninth main bearings under impact conditions can work normally.

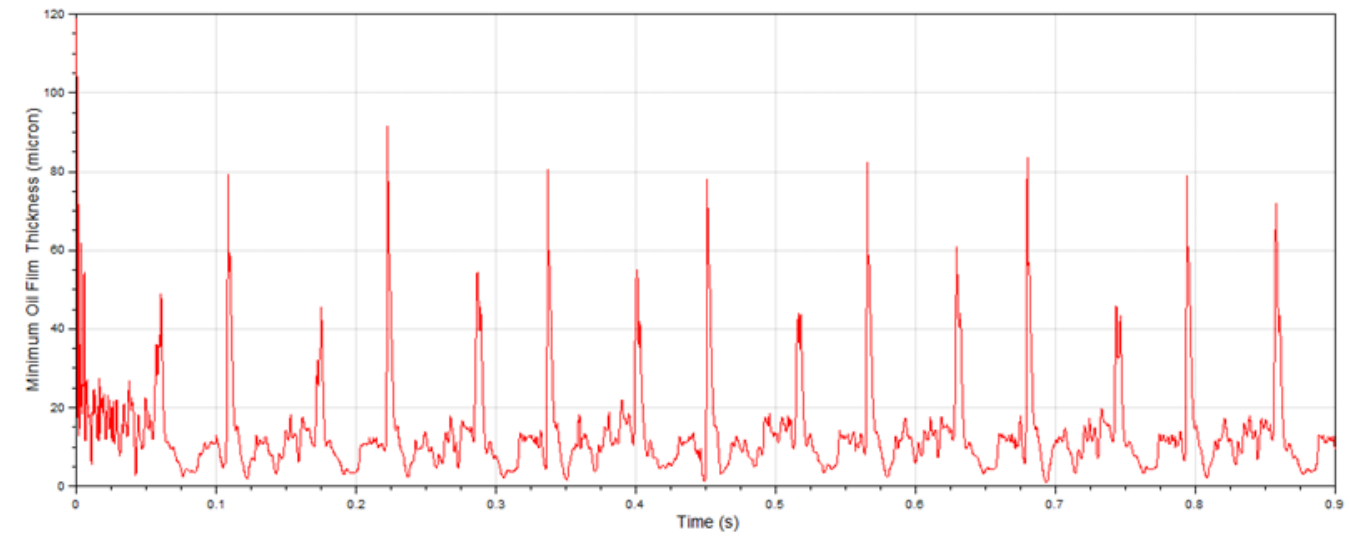

Figure 13. The minimum oil film thickness curve of the ninth main bearing under impact condition.

In shock conditions, among the nine main bearings, the second and nith main bearings have an oil film thickness less than $1.5 \mu \mathrm{m}$ and are in poor working conditions. 
Figure 14a is the distribution map of the average oil film pressure of the second main bearing in $0-0.12 \mathrm{~s}$ in shock conditions. It can be seen that the distribution position of the high oil film pressure area is concentrated near the center position of the lower bush at $180^{\circ}$. The distribution area of the high oil film pressure is wide and is beneficial for the main journal working better in the lower bearing bush.

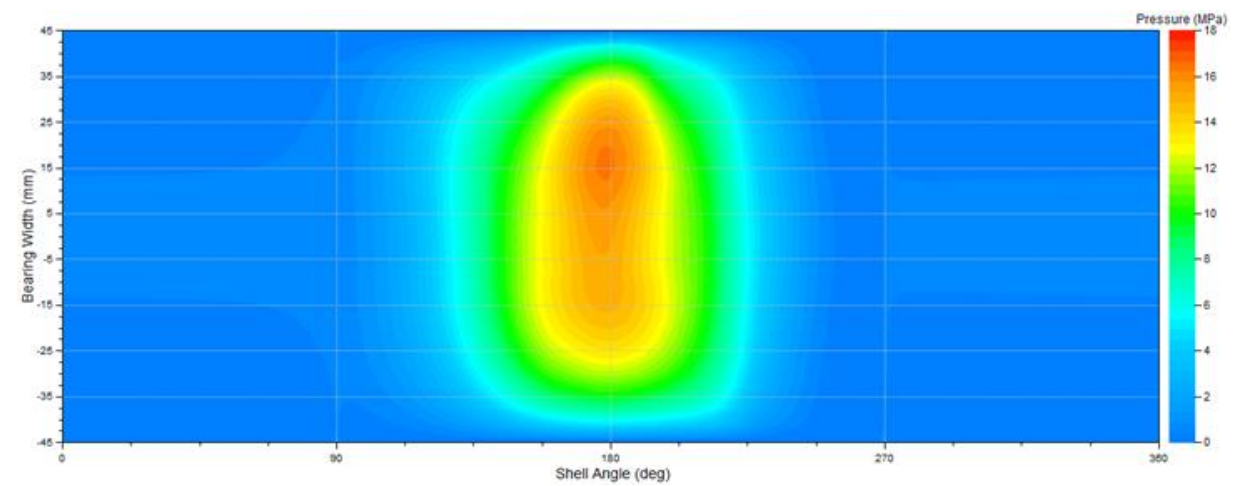

(a)

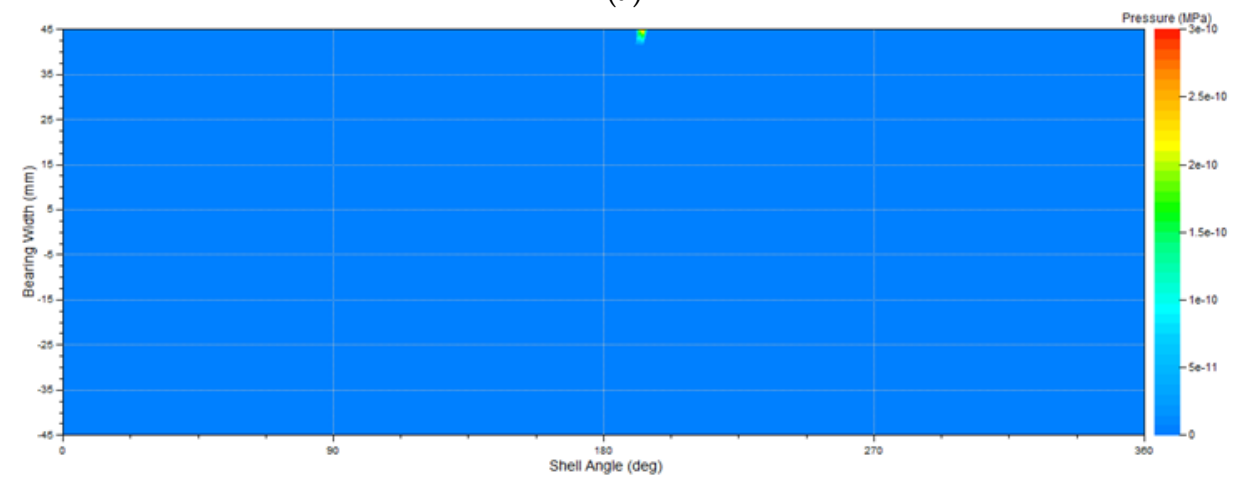

(b)

Figure 14. Distribution map of the average oil film pressure and the average asperity contact pressure of the second main bearing in shock condition in 0 to $0.12 \mathrm{~s}$. (a) Distribution map of the average oil film pressure of the second main bearing. (b) Distribution map of the average asperity contact pressure of the second main bearing.

Figure $14 \mathrm{~b}$ shows the average asperity contact pressure distribution map of the second main bearing in $0-0.12 \mathrm{~s}$ in shock conditions. The asperity contact area only accounts for a very small proportion of the entire bearing bush. The asperity contact position of the second main bearing is at the edge of the bearing shell near the $180^{\circ}$ position of the lower bush.

Figure 15a is the distribution map of the average oil film pressure of the ninth main bearing in $0-0.12 \mathrm{~s}$ in shock conditions. The high oil film pressure area of the ninth main bearing bush is distributed near the edge of the bearing shell because the ninth main bearing is at the output end of the block. The cylinders are located on the one side of the ninth main bearing. The area of high oil film pressure is not in the center of the bearing bush.

Figure $15 \mathrm{~b}$ shows the average asperity contact pressure distribution map of the ninth main bearing in $0-0.12 \mathrm{~s}$ in shock conditions. The asperity contact area is small compared with the entire bearing bush. The asperity contact position of the ninth main bearing is at the edge of the bearing shell near the $90^{\circ}$ position of the lower bush.

It can be seen from Figures 14 and 15, in shock environment, the working state of the second and ninth main bearing is in safe condition. 


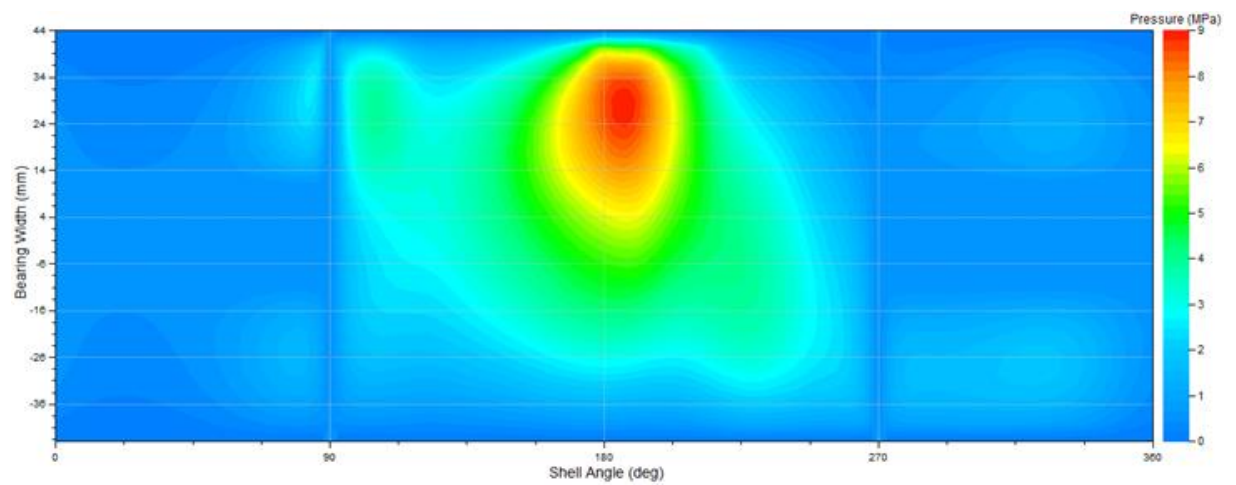

(a)

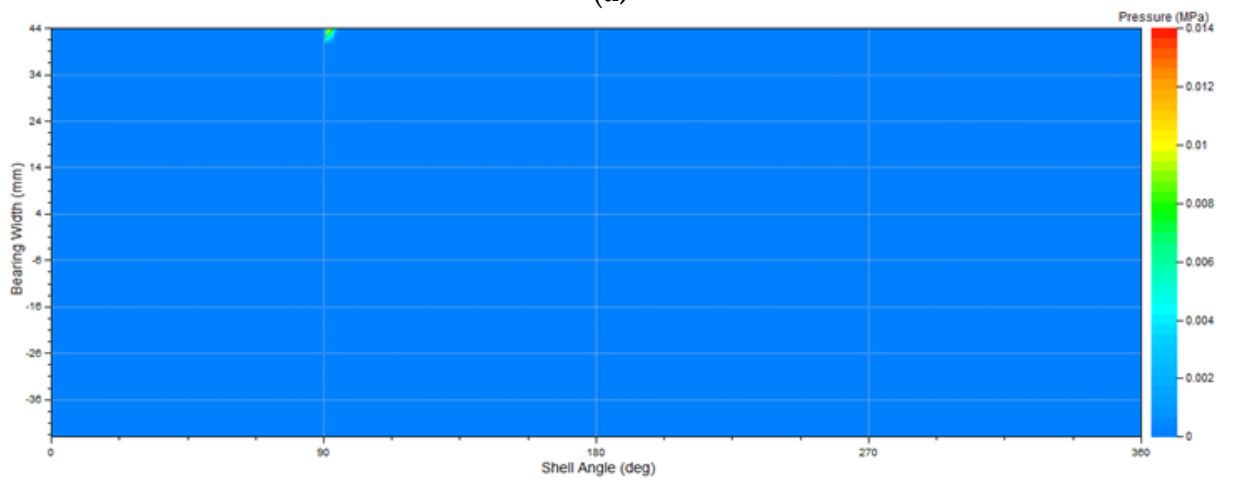

(b)

Figure 15. Distribution map of the average oil film pressure and the average asperity contact pressure of the ninth main bearing in shock condition in 0 to $0.12 \mathrm{~s}$. (a) Distribution map of the average oil film pressure of the ninth main bearing. (b) Distribution map of the average asperity contact pressure of the ninth main bearing.

\subsubsection{Crankshaft Stress of Diesel Engine with Shock Absorbers in Impact Condition}

As shown in Figure 16, it is the peak crankshaft stress curve in impact condition within 0 to 0.9 s. In Figure 16, it can be noticed that between 0 and 0.05 s, there are two peak crankshaft stresses, $432 \mathrm{MPa}$ and $442 \mathrm{MPa}$, which are significantly higher than the peak crankshaft stress within 0.05 to $0.9 \mathrm{~s}$. This abnormal results are caused by insufficient convergence in the initial stage of $0-0.05 \mathrm{~s}$ of the simulation. After the subsequent calculation time, the crankshaft stress curve gradually becomes stable.

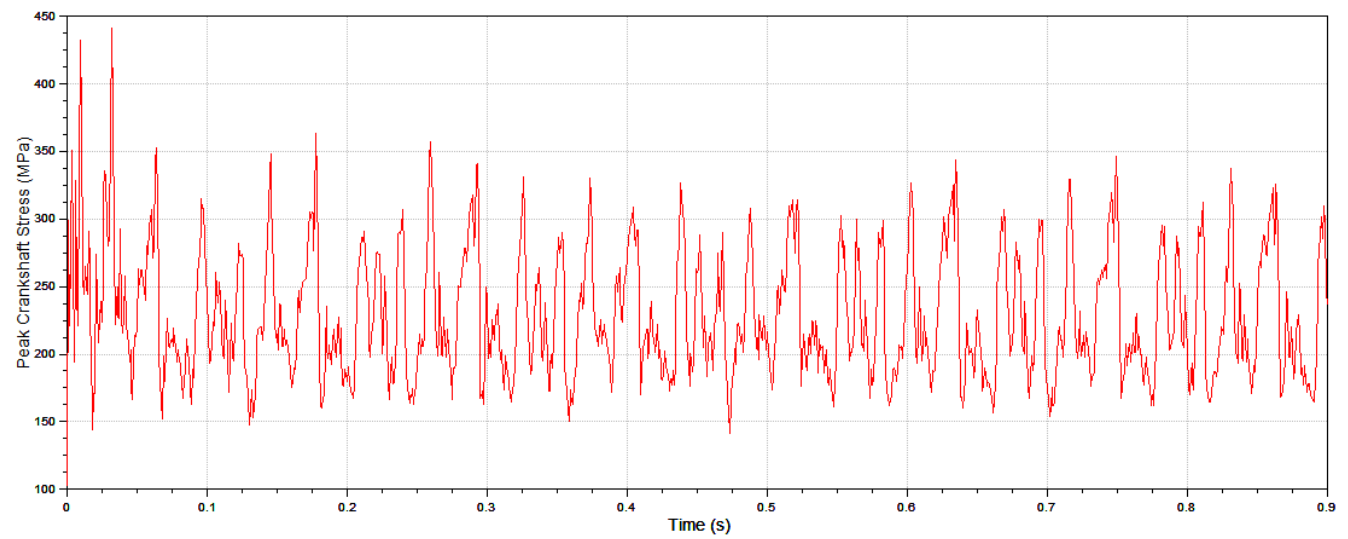

Figure 16. Peak crankshaft stress curve under impact condition within 0 to $0.9 \mathrm{~s}$.

Within $0.05-0.9 \mathrm{~s}$, the maximum crankshaft stress in impact conditions is $363 \mathrm{MPa}$ at $0.177778 \mathrm{~s}$ at the eighth crank pin, as shown in Figure 17. That does not exceed the yield limit of the crankshaft material $(650 \mathrm{MPa})$ with a large safety margin. 


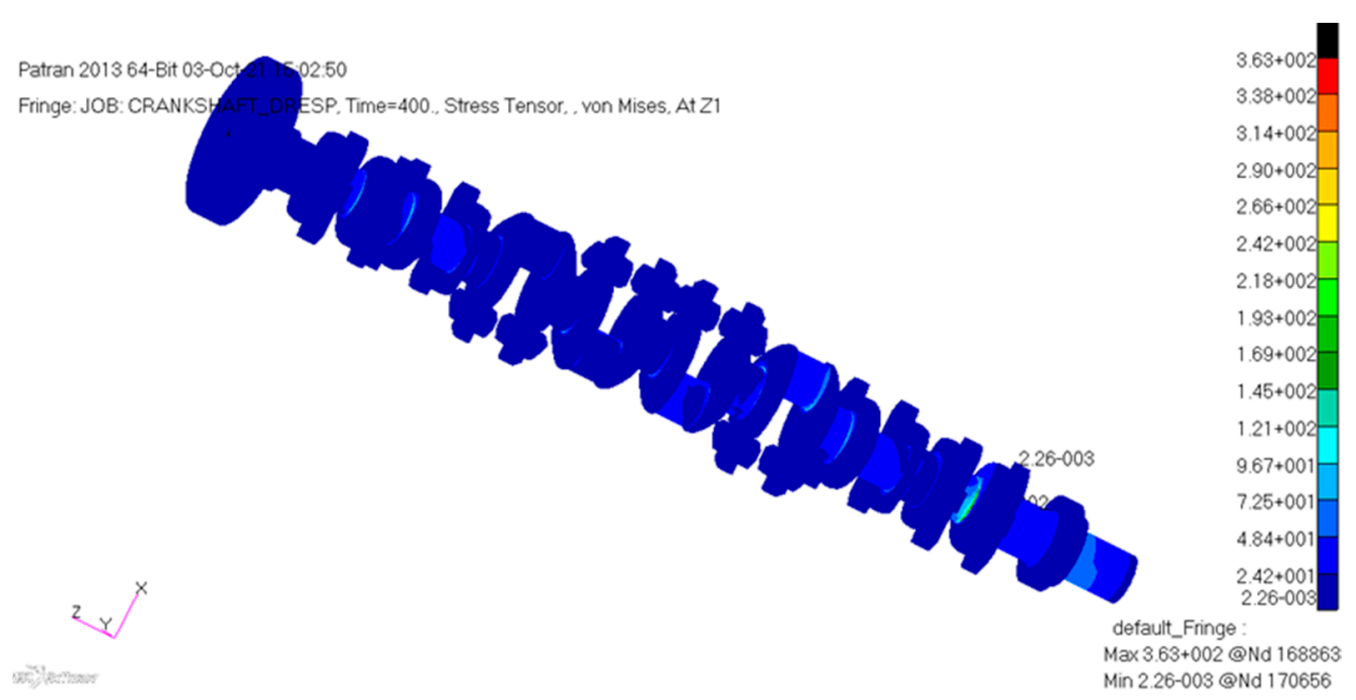

Figure 17. Under impact condition, the maximum crankshaft stress is $363 \mathrm{MPa}$ at $0.177778 \mathrm{~s}$, which is located at the eighth crank pin.

In short, in 0-0.9 s, the crankshaft stress in impact conditions does not exceed the yield limit of the crankshaft material with a large safety margin, so the crankshaft of the diesel engine with shock absorber is safe under external impact.

Through the calculation results, it can be found that when the shock absorber is installed, the main bearing can maintain the normal lubrication state, and the crankshaft stress does not exceed the yield limit, so the diesel engine with shock absorbers can work normally in impact conditions.

It can also find that, when the diesel engine equipped with shock absorbers, the main bearing lubrication results and crankshaft stress results in the external shock condition are very similar to the one in normal conditions. That means the shock absorbers can protect the diesel engine from external shock.

\subsection{Calculation of Diesel Engine without Shock Absorbers in Impact Condition}

This section will calculate the 16-cylinder V-type diesel engine without the shock absorbers under external shock condition. The external shock is still loaded through the diesel engine base.

\subsubsection{Main Bearing Lubrication of Diesel Engine without Shock Absorbers in} Impact Condition

Shown in Figure 18 is the peak oil film pressure curve of the first main bearing of the diesel engine without shock absorbers under an external impact environment. In Figure 18, at $0.863831 \mathrm{~s}$, there is a peak oil film pressure of $2549.09 \mathrm{MPa}$ at the first main bearing, which far exceeds the peak oil film pressure required by the AVL bearing evaluation point (must be less than 100-150 MPa).

As shown in Figure 19, it is the peak asperity contact pressure curve of the first main bearing of the diesel engine without shock absorber in the external impact environment. At $0.361813 \mathrm{~s}$, there is an asperity contact pressure of up to $215.686 \mathrm{MPa}$ at the first main bearing, which far exceeds the asperity contact pressure recommended value required by the AVL bearing evaluation point (must be less than $50 \mathrm{MPa}$ ). 


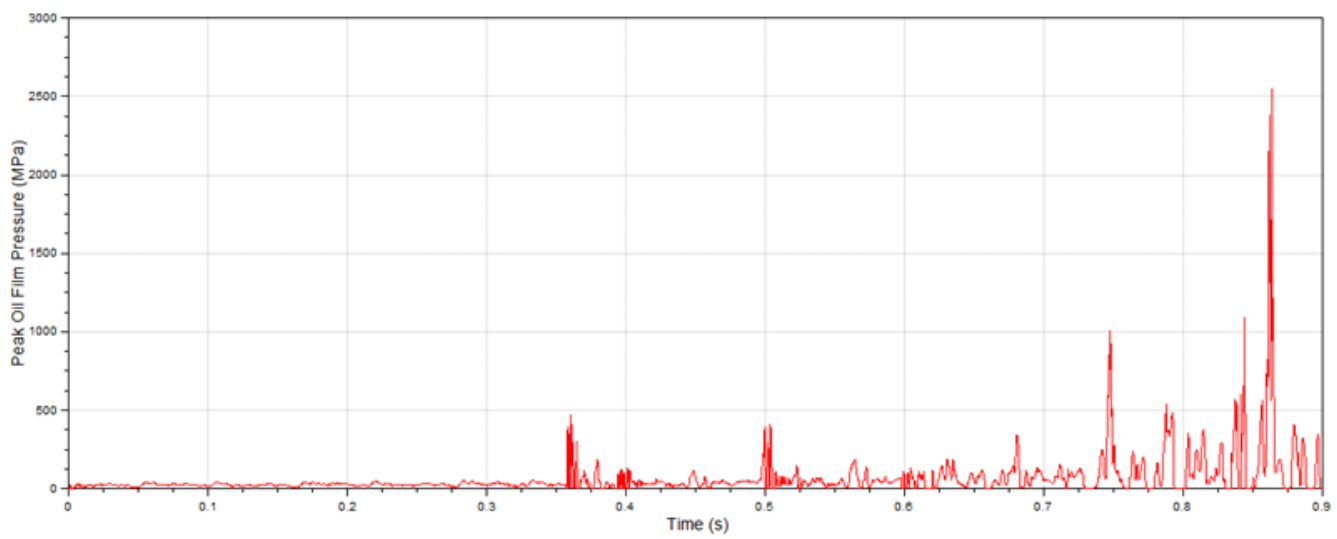

Figure 18. The peak oil film pressure curve of the first main bearing of the diesel engine without shock absorbers under the external shock environment. The $\mathrm{x}$-axis represents time in seconds, and the $\mathrm{y}$-axis represents the peak oil film pressure in units $\mathrm{MPa}$.

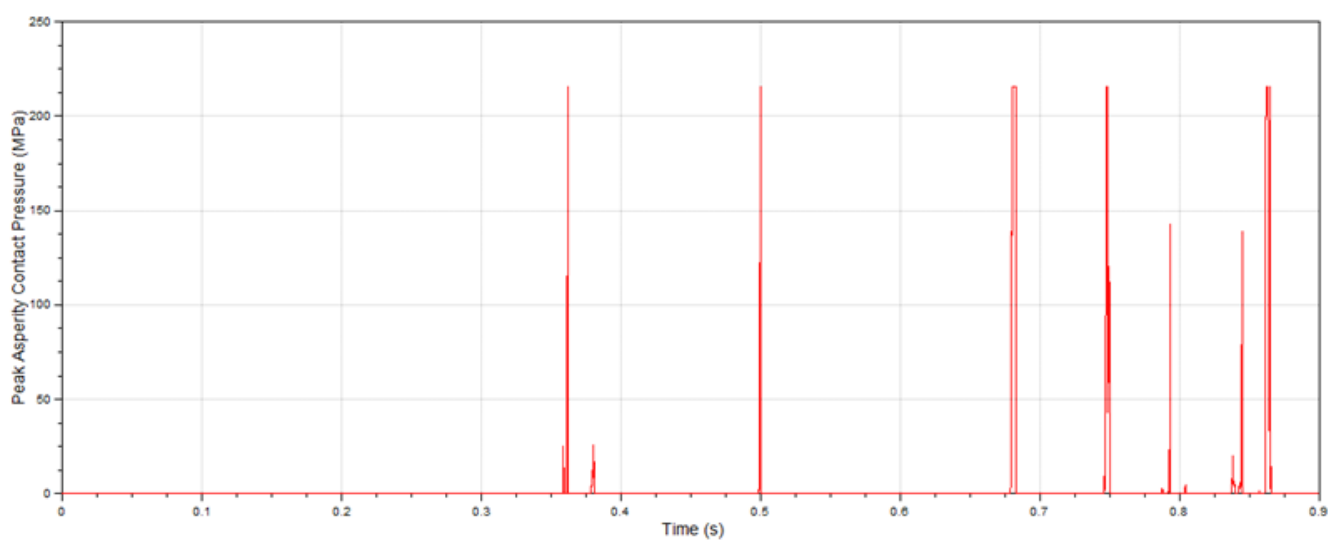

Figure 19. The peak asperity contact pressure curve of the first main bearing of a diesel engine without shock absorbers under the external shock environment. The x-axis represents time in seconds, and the $\mathrm{y}$-axis represents the peak asperity contact pressure in units MPa.

As shown in Figure 20, it is the minimum oil film thickness curve of the first main bearing of the diesel engine without shock absorbers in an external impact environment. At $0.361298 \mathrm{~s}$, there is a minimum oil film thickness of $0.0111803 \mu \mathrm{m}$ at the first main bearing, which is much lower than the AVL bearing evaluation requirement (must be greater than $1.5 \mu \mathrm{m})$.

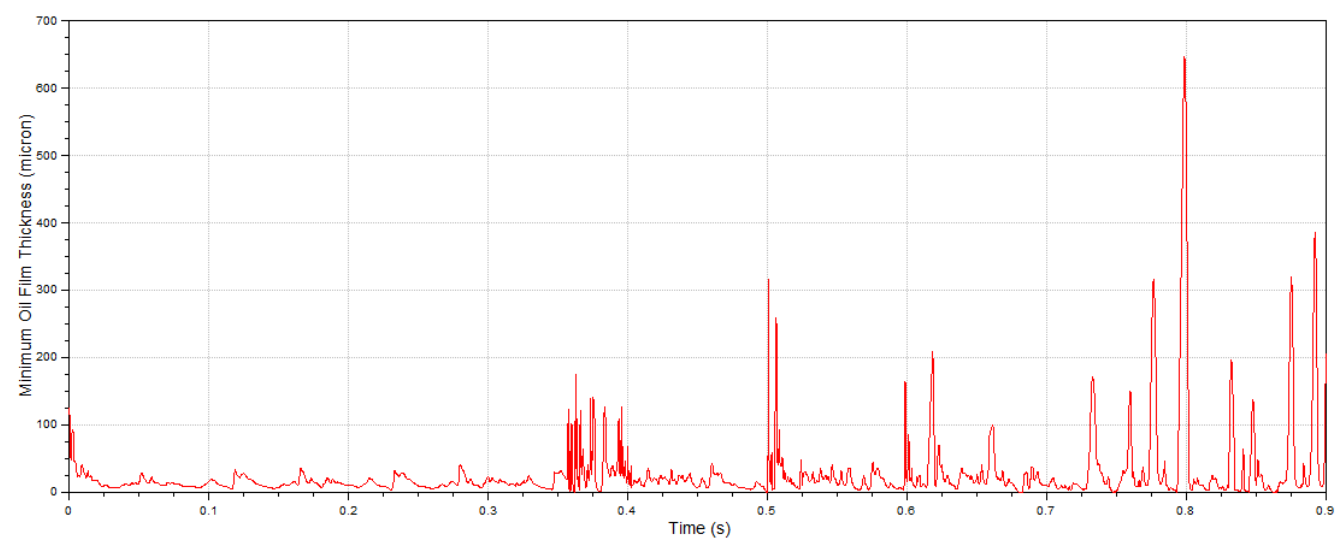

Figure 20. The minimum oil film thickness curve of the first main bearing of a diesel engine without shock absorbers under the external shock environment. 
Combining the results of evaluation indicators such as peak oil film pressure, peak asperity contact pressure, and minimum oil film thickness, it can be seen that the lubrication state of the main bearings of the diesel engine without the shock absorbers is unusable under external impact.

\subsubsection{Crankshaft Stress of Diesel Engine without Shock Absorbers in Impact Condition}

As shown in Figure 21, the crankshaft stress at the first crank pin at $0.359048 \mathrm{~s}$ has reached $865 \mathrm{MPa}$, which has exceeded the yield limit of the crankshaft material $(650 \mathrm{MPa})$. Therefore, the diesel engine without the shock absorbers will not work normally due to irreversible plastic crankshaft deformation under external impact.

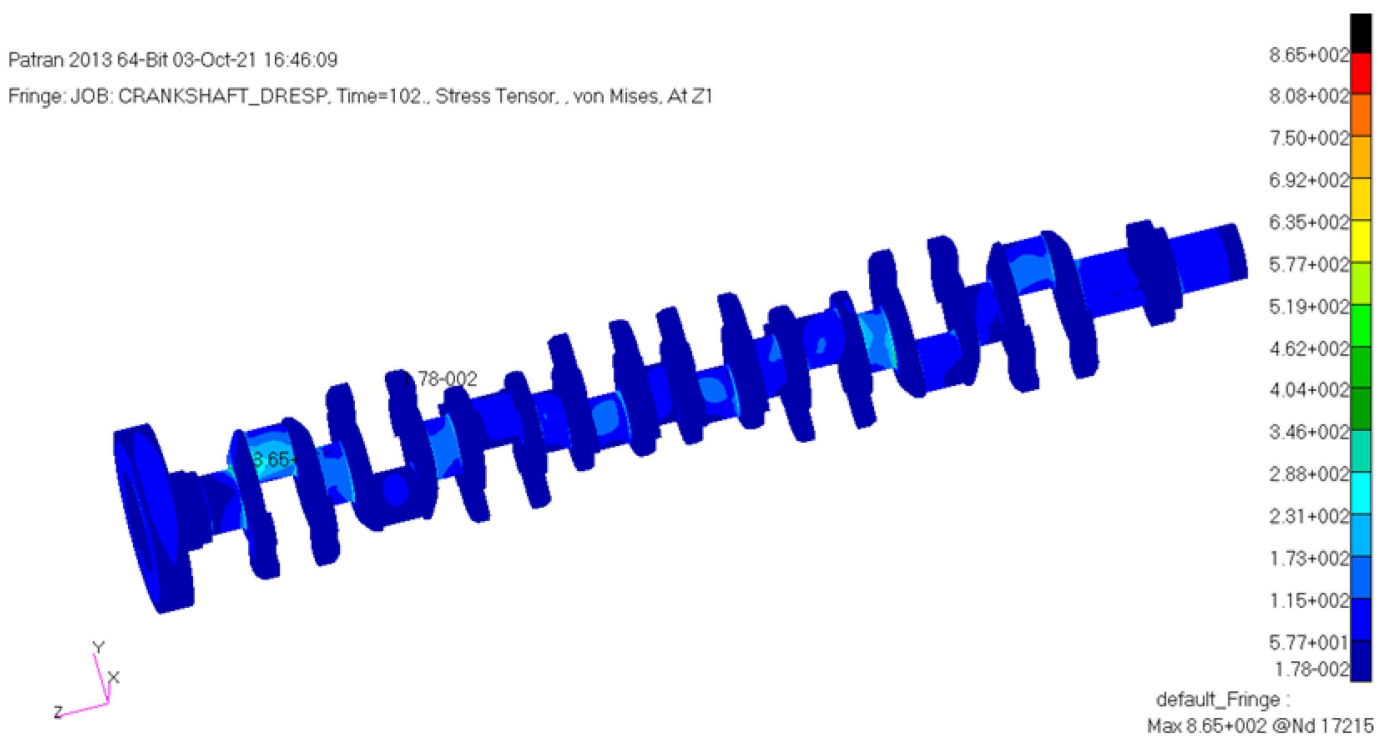

Figure 21. For a diesel engine without shock absorbers, the crankshaft stress reached $865 \mathrm{MPa}$ at the first crank pin at 0.359048 s under external impact.

Combining the calculation results of the main bearing lubrication and the crankshaft stress, the diesel engine without shock absorbers will not work normally under the external impact.

This calculation result is consistent with the facts observed by Chen Ji [62] in a underwater explosion experiment of a real ship: "The test results show that under the same test environment, rigidly mounted diesel engines (without the shock absorber) are more likely to be damaged than elastically mounted diesel engines (with the shock absorber). Most of the impact energy was absorbed by shock protection device".

Therefore, in order to improve the survivability of naval diesel engines on the battlefield, it is strongly recommended to install shock absorbers or other anti-shock protection devices.

\section{Conclusions}

This research aims at using a elastohydrodynamic lubrication method in the main bearings of the diesel engine in external shock conditions. The external shock is equivalent to the interference on the elastohydrodynamic lubrication calculation. Whether the elastohydrodynamic lubrication algorithm can complete the calculation under interference is the key point to the study. By adopting a very small calculation step size, a high number of iterations, and increasing the stiffness of the thrust bearing, the elastohydrodynamic lubrication algorithm can be successfully completed under the external impact environment. The calculation results of the accelerations on engine block feet have the similar trend with experiment results. Diesel engine with and without shock absorbers in external shock con- 
dition are calculated. This calculation model can also be used for diesel engine dynamics calculations and main bearing lubrication calculations under normal working conditions.

The main contribution of this research is to use an example of a V-type 16-cylinder diesel engine to show that the elastohydrodynamic lubrication algorithm can be used for the lubrication calculation of the main bearing of the diesel engine under the impact environment and summarize the parameter settings that enable the lubrication calculation to be completed. It can provide reference for similar research in the future.

The advantage of this research is that using elastohydrodynamic lubrication algorithm in the main bearing of diesel engine makes the simulation more realistic. The main bearing lubrication results provide a new evaluation method for the diesel engine antishock research.

The difficulty of this research is that it takes a lot of time to perform trial calculations to adjust the calculation parameters. Compared with the spring damping model, the robustness of the elastohydrodynamic lubrication algorithm is not good enough. It takes a lot of time to adjust the calculation parameters and find the possible reasons for the stagnation of the simulation calculation based on the feedback of the calculation results.

The drawbacks of the research also lie in that the robustness of the elastohydrodynamic lubrication algorithm in external shock is not good enough. Imagine a case of high external impact amplitude or long shock duration time: Even if small calculation steps, high iterations, and high spring stiffness of joints are adopted, a lot of time was spent on trial calculations to adjust the calculation parameters, and the simulation calculation may still not converge. The uncertainty of completion of calculation in severe shock may cause difficulties in the popularization of the elastohydrodynamic lubrication algorithm in diesel engine anti-shock research.

There are still some shortcomings in this research. In order to simplify the simulation, the foundation of the diesel engine is simplified to a rigid body without considering the elasticity of the foundation. The influence of the bolts' preload, frequency, displacement, and position on the main bearing covers are not considered. The change in the stiffness and damping of the shock absorber with frequency and displacement is not considered. No sensitivity analysis was conducted on the obtained results. These influencing factors will be considered in the future research.

Author Contributions: Conceptualization, L.C., D.X. and X.S.; methodology, L.C., D.X. and X.S.; software, L.C.; validation, L.C. and Z.H.; formal analysis, L.C., D.X. and X.S.; data curation, D.H.; writing-original draft preparation, L.C. All authors have read and agreed to the published version of the manuscript.

Funding: This research received no external funding.

Institutional Review Board Statement: Not applicable.

Informed Consent Statement: Not applicable.

Data Availability Statement: No data were used to support this research.

Acknowledgments: The first author thanks the helpful discussion with Yujun Liu, fron the National Engineering Research Center of Shipbuilding (Dalian University of Technology, China), and thanks the Key Laboratory of Ocean Energy Utilization and Energy Conservation of Ministry of Education of China (Dalian University of Technology, China) for the technical and scientific support to this work.

Conflicts of Interest: The authors declare no conflict of interest.

\section{References}

1. Liu, J.H. Theory and Its Application of Ship Dynamic Responses to Non-Contact Underwater Explosions. Ph.D. Thesis, China Ship Scientific Research Center, Wuxi, China, March 2002.

2. Alexander, J.E. Nonlinear system mode superposition given a prescribed shock response spectrum input. In Proceedings of the IMAC-XX Conference and Exposition on Structural Dynamics-Smart Structures and Transducers, Los Angeles, CA, USA, 4-7 February 2002. 
3. James, P.; Roggeman, B. Mechanical shock testing and modeling of PC motherboards. In Proceedings of the IEEE Electronic Components and Technology Conference, Las Vegas, NV, USA, 1-4 June 2004.

4. Jayson, E.M. Numerical and Experimental Investigations of a Hard Disk Drive Subject to Shock and Vibration. Ph.D. Thesis, University of California, San Diego, CA, USA, 2003.

5. Wang, Y.; Hua, H.X. Modern Ship Shock Theory and Its Application, 1st ed.; China Science Publishing \& Media Ltd.: Beijing, China 2005; pp. 1-2.

6. Liu, S.J.; Bao, G.Z.; Chen, H.Q.; Chen, X.C.; Yao, S.G. Shock response analysis of crank and connecting rod mechanism of 12 VPA6 marine diesel engine. Chin. Intern. Combust. Engine Eng. 2007, 28, 39-42.

7. Wang, C.Y.; Chang, H.B.; Zheng, R.B.; Wang, Y. Shock dynamics simulation of crankshaft system based on DYTRAN. Chin. Intern. Combust. Engine Eng. 2009, 30, 87-92.

8. Ma, B.J.; Zhang, H.; Wang, Z.G. Dynamic analysis of shock response for crank and connecting rod mechanism in diesel engines. Noise Vib. Control 2013, 33, 32-35.

9. Lu, K.M.; Wang, Y. Analysis of shock dynamics on diesel engine crank and connecting rod mechanism. J. Nav. Univ. Eng. 2011, $23,84-87$.

10. Ming, Z.J. Analysis for Dynamic Characteristics and Shocking Response of a Diesel Engine Crankshaft System. Master's Thesis, Dalian University of Technology, Dalian, China, 2008.

11. Ding, J.H.; Song, Y.L.; Wang, H.; Ren, J.J.; Liu, B. Parallel computing for large scale anti-shock dynamic simulation of diesel engine. J. Vib. Shock. 2014, 33, 163-167.

12. Zhao, J.H.; Wang, Y.; Gao, H.B.; Sun, Y.P. Shock limited load of equipment and analysis examples. Noise Vib. Control 2012, 32, 120-124.

13. Gao, H.P.; Song, J.L.; Feng, L.H.; Shen, X.L. Method research of the test point arrangement for marine diesel in anti-shock test. China Meas. Test. 2016, 42, 140-144.

14. Zhao, J.H.; Wang, Y.; Ji, C.; Yang, Y. Strength analysis of the main fixed assembly of diesel engine subjected to underwater explosion. J. Mech. Strength 2008, 30, 707-712.

15. Ji, C.; Wang, Y.; Yang, L.; Feng, L.H. Time domain analysis on shock response of main components of diesel. Acta Armamentarii 2011, 32, 391-396.

16. Wu, W.B. Simulation on anti-shock characteristic of diesel engine. Ship Ocean Eng. 2010, 39, $63-65$.

17. Ji, C.; Wang, Y.; Ao, C.Y.; Wu, J.B. Shock response analysis of marine diesel engine on dynamic operation. Ship Eng. 2010, 32, 13-16.

18. Wang, Y.; Zhao, J.H.; Du, J.Y.; Mu, C. Simulation on antishock performance of a marine diesel engine by using finite element calculation based on multibody dynamics. J. Vib. Shock. 2009, 28, 87-90.

19. Xiao, Y.L. Research on Vibration and Shock-Resistant of Marine Diesel. Master's Thesis, Jiangsu University of Science and Technology, Zhenjian, China, March 2014.

20. Sun, J.; Gui, C.L.; Wang, J.F.; Pan, Z.D. Analysis of bearing tribology performance considering crankshaft deformation in crankshaft-bearing system. Trans. CSICE 2007, 25, 258-264.

21. He, Z.X.; Gui, C.L.; Li, Z.; Sun, J. Couple research on dynamics and tribology of crankshaft-bearing system considering misalignment caused by elastic deflection. Trans. Chin. Soc. Agric. Mach. 2007, 38, 5-10.

22. Marian, M.; Bartz, M.; Wartzack, S.; Rosenkranz, A. Non-dimensional groups, film thickness equations and correction factors for elastohydrodynamic lubrication: A review. Lubricants 2020, 8, 95. [CrossRef]

23. Marian, M.; Grützmacher, P.; Rosenkranz, A.; Tremmel, S.; Mücklich, F.; Wartzack, S. Designing surface textures for EHL point-contacts-transient 3D simulations, meta-modeling and experimental validation. Tribol. Int. 2019, 137, 152-163. [CrossRef]

24. Yang, F.Q.; Liu, X.; Jiang, J.W. Current progress of elasto-hydrodynamic lubrication on mechanical parts with higher pairs. Lubr. Eng. 2019, 44, 135-140.

25. Zhao, J.J.; Wang, Y.Q. Present situation and development trend of elastohydrodynamic lubrication for modified helical gear. J. Mach. Des. 2018, 35, 53-57.

26. Xue, H.; Wang, J.G.; Hong, Y.F. Elastohydrodynamic lubrication analysis on line contact lubricated with grease. Lubr. Eng. 2017, $42,12-16$.

27. Zhou, Y.B.; Wang, Y.Q.; Wei, C.; Long, S.W. Influence of interfacial modification on EHL of journal bearing. J. Mech. Transm. 2019, $43,27-31$.

28. Shen, J.L.; Xue, Z.T.; Heng, C.F.; Liu, X.J. Elastic deformations of surface under EHL point contact. China Mech. Eng. 2019, 30, 1696-1702.

29. Zhang, T.; Chen, X.Y.; Chen, S.J.; Gu, J.M. Study on starved oil elastohydrodynamic lubrication model and experiments of multi-point contacts. Lubr. Eng. 2020, 45, 125-134.

30. Jin, W.; Guo, F.; Jing, Z.G. Reconsideration of Hamrock-Dowson Formula for Elliptic Contact Elastohydrodynamic Lubrication. 2021. Available online: https://kns.cnki.net/kcms/detail/62.1095.O4.20210220.1414.025.html (accessed on 20 February 2021).

31. Meng, F.M.; Zhang, W.M. Elastohydrodynamic lubrication of elliptical contact considering effect of inertia of lubrication film. Tribology 2019, 39, 585-592.

32. Yang, G.D.; Cao, Y.P.; Zhang, W.P.; Ming, P.J.; Li, L.Y. Coupling analysis of thermal elastic hydrodynamic lubrication of functionally graded main bearing. Trans. CSICE 2021, 39, 459-465. 
33. Li, C.J.; Zhao, J.S.; Zhu, G.X.; Li, X.C.; Zhang, G.D. Influence of crankshaft journal profile on lubrication of main bearing. Lubr. Eng. 2021, 46, 51-56.

34. Ren, P.R.; Zuo, Z.X.; Cheng, Y.; Zhang, Z.W. Effect of the side bolts on the dynamic and static characteristics of the internal combustion engine's main bearing. J. Mach. Des. 2020, 37, 14-20.

35. Teng, X.B.; Zhang, J.D.; Ye, W.Q. Characteristic analysis of diesel engine main bearing lubrication based on thermo-elastic hydrodynamic pressure. Ship Eng. 2016, 238, 61-64.

36. Shi, L.; Zhang, H.B.; Li, L.T.; Liang, G. Finite element analysis and structural optimization of main bearing block for a marine diesel engine. Diesel Engine 2016, 38, 20-24.

37. Li, H.; Zhao, J.S.; Cui, S.X.; Zhang, Z.W.; Yang, S.B. Influence of surface profile on lubrication performance of engine main bearings. Lubr. Eng. 2018, 43, 49-54.

38. Zhou, W.; Liao, R.D. Thermo-elasto-hydrodynamic mixed lubrication analysis of main bearing for high power-density diesel engine. Trans. CSICE 2016, 34, 370-378.

39. Liu, C.P.; Zhao, B.; Li, W.; Lu, X. Effects of bushing profiles on the elastohydrodynamic lubrication performance of the journal bearing under steady operating conditions. Mech. Ind. 2019, 20, 207-220. [CrossRef]

40. Zhang, J.H.; Zhang, G.C.; He, Z.P.; Ma, L.; Ma, W.P. Optimization of crankshaft-bearing lubricating characteristics based on orthogonal experiment and neural network. Trans. CSICE 2011, 29, 461-467.

41. Wang, J.; Zhang, J.H.; Lin, J.W.; Ma, L. Study on lubrication performance of journal bearing with multiple texture distributions. Appl. Sci. 2018, 8, 244. [CrossRef]

42. Liu, K.; Chen, R.; Zhao, J.H.; Wang, F.Y.; Zhao, B. Lubrication characteristics analysis and variable wall thickness optimization design of a diesel engine main bearing under different crankshaft balance ratios. Chin. Intern. Combust. Engine Eng. 2021, 42, $54-61$.

43. Yan, X.Y.; Cui, Y.; Fu, Y.; Cheng, D.; Dong, J.J. Elasto-hydrodynamic lubrication analysis of main bearing for a low speed marine diesel engine. Diesel Engine 2020, 42, 22-29.

44. Yan, X.Y.; Cui, Y.; Fu, Y.; Cheng, D.; Dong, J.J. Stiffness matching design of bedplate for low speed two-stroke marine diesel engine based on dynamics and coupling lubrication. Ship Eng. 2019, 41, 52-58.

45. Zhou, J.H.; Xu, M.; Wang, B. A novel method studying the effects of journal straightness in three-dimensional space on lubrication of bearing. In Proceedings of the SAE World Congress Experience, Detroit, MI, USA, 4-6 April 2017.

46. Feng, X.K.; Yang, L.H. Analysis on thermoelasto-hydrodynamic lubrication characteristics of tilting pad thrust bearing under heavy load. J. Aerosp. Power 2021, 36, 1861-1870.

47. Qian, W.D.; Jin, G.; Tang, L.M. Lubrication characteristic analysis of three-dimensional thermal-elastic flow for the dynamic pressure thrust bearing. Pump Technol. 2020, 2020, 16-21.

48. Wang, J.X.; Ni, X.K.; Han, Y.F.; Xiang, G.; Xiao, K. Mixed thermoelastohydrodynamic lubrication investigation of misaligned journal bearing. J. Cent. South Univ. Sci. Technol. 2019, 50, 2425-2434.

49. Mourelatos, Z.P. A crankshaft system model for structural dynamic analysis of internal combustion engines. Comput. Struct. 2001, 79, 2009-2027. [CrossRef]

50. Offner, G. Simulation of the dynamics of internal combustion engines considering oil film lubricated contacts. In Proceedings of the European Congress on Computational Methods in Applied Sciences and Engineering, Vienna, Austria, 10-14 September 2012.

51. Ma, M.T.; Offner, G.; Loibnegger, B.; Priebsch, H.H.; McLuckie, I. A fast approach to model hydrodynamic behavior of journal bearings for analysis of crankshaft and engine dynamics. In Proceedings of the 30th Leeds-Lyon Symposium on Tribology, Lyon, France, 2-5 September 2003.

52. Caika, V.; Bukovnik, S.; Offner, G.; Bartz, W.J. Elasto-hydrodynamic journal bearing model with pressure, temperature and shear rate dependent viscosity. In Proceedings of the International Conference on Tribology (AITC-AIT), Parma, Italy, 20-22 September 2006.

53. Caika, V.; Offner, G.; Bukovnik, S.; Bartz, W.J. Modeling of shear thinning effects in EHD lubrication of combustion engine journal bearings. In Proceedings of the European Conference on Tribology (ECOTRIB), Ljubljana, Slovenia, 12-15 June 2007.

54. Priebsch, H.H.; Affenzeller, J.; Kuipers, G. Prediction technique of vibration and noise in engines. In Proceedings of the IMechE Conference on Quiet Resolutions: Powertrain and Vehicle Noise Refinement, London, UK, 9-11 October 1990.

55. Priebsch, H.H.; Affenzeller, J.; Gran, S. Prediction technique for stress and vibration of non-linear supported rotating crankshafts. J. Eng. Gas Turbines Power 1993, 115, 711-720. [CrossRef]

56. Parikyan, T.; Priebsch, H.H. Structured model of crankshaft in the simulation of engine dynamics with AVL EXCITE. In Proceedings of the ASME Internal Combustion Engine Division Fall Technical Conference, Argonne, IL, USA, 23-26 September 2001.

57. Greenwood, J.A.; Williamson, J.B.P. The contact of two nominally flat surfaces. Proc. Roy. Soc. 1966, 295, 300-319. [CrossRef]

58. Greenwood, J.A.; Tripp, J.H. The contact of two nominally flat rough surfaces. Proc. Inst. Mech. Eng. 1971, 185, 48-71. [CrossRef]

59. Keil, A.H. The Response of Ships to Underwater Explosions; Armed Services Technical Information Agency: Arlington, VA, USA, 1961.

60. EHD Reference Manual of AVL EXCITE Power Unite Software Help Documents.

61. Mou, S.K. Analysis and improvement of calculating results for 16V240ZJB diesel engine bearings. Diesel Locomot. 1995, 1995, 30-35.

62. Ji, C.; Wang, Z.G.; Wang, Y.; Zhao, J.H. Anti-shock capability of marine diesel in ship shock trial. Ship Sci. Technol. 2010, 32, 27-30. 